\title{
A Variational Approach for Predicting the Load Deformation Response of a Double Stretched Membrane Reflector Module
}

\author{
L. M. Murphy
}

October 1985

Prepared under Task No. 5102.31

FTP No. 463

Solar Energy Research Institute

A Division of Midwest Research Institute

1617 Cole Boulevard

Golden, Colorado 80401

Prepared for the

U.S. Department of Energy

Contract No. DE-AC02-83CH10093 


\section{PREFACE}

The research and development described in this document was conducted within the U.S. Department of Energy's Solar Thermal Technology Program. The goal of this program is to advance the engineering and scientific understanding of solar thermal technology and to establish the technology base from which private industry can develop solar thermal power production options for introduction into the competitive energy market.

Solar thermal technology concentrates the solar flux using tracking mirrors or lenses onto a recelver where the solar energy is absorbed as heat and converted into electricity or incorporated into products as process heat. The two primary solar thermal technologies, central recelvers and distributed receivers, employ various point and line-focus optics to concentrate sunlight. Current central recelver systems use fields of heliostats (two-axis tracking mirrors) to focus the sun's radiant energy onto a single, towermounted receiver. Parabolic dishes up to 17 meters in diameter track the sun in two axes and use mirrors or Fresnel lenses to focus radiant energy onto a recelver. Troughs and bowls are line-focus tracking reflectors that concentrate sunlight onto recelver tubes along their focal 1ines. Concentrating collector modules can be used alone or in a multimodule system. The concentrated radiant energy absorbed by the solar thermal receiver is transported to the conversion process by a circulating working fluid. Receiver temperatures range from $100^{\circ} \mathrm{C}$ in low-temperature troughs to over $1500^{\circ} \mathrm{C}$ in dish and central recelver systems.

The Solar Thermal Technology Program is directing efforts to advance and improve each system concept through solar thermal materials, components, and subsystems research and development and by testing and evaluation. These efforts are carried out with the technical direction of DOE and its network of national laboratorles that works with private industry. Together they have established a comprehensive, goal-directed program to improve performance and provide technically proven options for eventual incorporation into the Nation's energy supply.

To successfully contribute to an adequate energy supply at reasonable cost, solar thermal energy must be economically competitive with a variety of other energy sources. The Solar Thermal Program has developed components and system-1evel performance targets as quantitative program goals. These targets are used in planning research and development activities, measuring progress, assessing alternative technology options, and developing optimal components. These targets will be pursued vigorously to ensure a successful program.

This report presents work supported by the Office of Solar Thermal Technology of the U.S. Department of Energy as part of the Solar Energy Research Institute research effort on innovative concentrators. The purpose is to document an analysis method, developed over the last year, that describes the response of stretched membrane reflector modules and is used in studying varfous design approaches and the system performance benefits of the stretched membrane modules. 
I would like to thank both Martin Scheve and Frank Wilkens of the U.S. Department of Energy for thefr support and to express appreclation to Danlel Sallis and David Simms for their assistance in preparing the numerical computations presented in this analysis.

The author would also like to thank the following non-SERI individuals for their helpful review of, and comments on, the draft document: Clay Mavis, Len Napolitano, Chris Tuan, Kumar Romahalli, Jon Peterka, David White, Barry Butler, Frank W1lkens, and Martin Scheve.

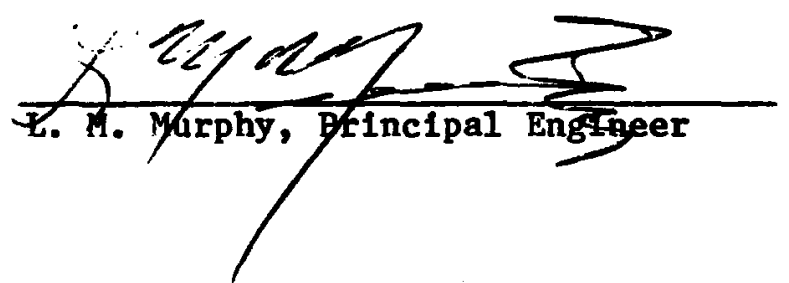

Approved for

SOLAR ENERGY RESEARCH INSTITUTE

Sals. 2hat

John P. Thornton, Manager

Thermal Systems and Englneering Branch

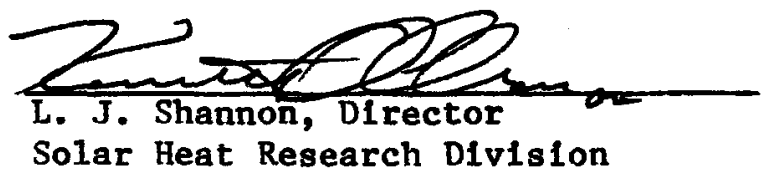




\section{SUMMARY}

\section{Objective}

The objective of the work presented in this report is to describe a new computer model that can estimate the structural and macroscopic optical surface performance under various loading conditions of various heliostat designs using a stretched membrane reflector module.

\section{Discussion}

The intent of the model is to provide a simple tool that can be used to increase our understanding of the structural response of stretched membrane modules and the effect that different design approaches have on the performance of these modules. This report extends earlier model work by considering a number of important design features that the previous model did not. Specifically, for loading normal to the plane of the membrane, the current model predicts the coupled membrane/frame response and considers the inplane stiffness effect of the membrane and nonuniform tension states in the membrane; the effect of different attachment schemes; and, most important, the impact of double-membrane designs. Note that the membrane is assumed to have no stiffness to bending but does have in-plane stiffness and that the tension increments in the membrane are small compared to the initial membrane pretension.

The model developed in this report is based on an incremental variational approach where large deformation, small strain theories are assumed. The Raylelgh Ritz procedure and a formalism similar to that used in finite element analyses are employed in describing the system stiffness. The solution is greatly simplified by expressing both the in-plane and out-of-plane membrane displacements as a function of the frame displacements. For in-plane membrane response, this is accomplished by using the membrane/frame compatibility conditions along with derived solutions for the classical plane stress elasticity boundary value problem.

Some of the important response phenomena and design considerations the model describes relative to the double-membrane concept include the following:

- Unlike the single-membrane designs, the double-membrane approach couples the in-plane membrane material stiffness with the deformation process even at low loads and low tension levels.

- Because of this membrane stiffness coupling, the double-membrane module is considerably stiffer to lateral loading than is the corresponding single-membrane design. This coupling and stiffening to lateral loading accrues by two mechanisms; $i_{\text {.e., }}$ by constraining the roll of the frame and by providing a bending rigidity contribution to the frame, which is analogous to a flange section.

- Attachment design and stiffness is an important design consideration since it determines how effectively the stiffness of the membrane can be coupled with the frame. It is particularly important in the design of double-membrane designs with stiff membranes. 


\section{Conclusions and Recommendations}

The model agrees quite well with the significantly more comprehensive NASTRAN computer model over a range of design parameters. Specifically, the model accurately reproduces the NASTRAN results for the dominant response phenomena corresponding to laterally loaded, stretched membrane modules, and for either single- or double-membrane designs as well as different membrane attachment approaches, as long as the model assumptions are adhered to. Further, the model faithfully predicts the interaction of the membrane/frame combination and the effect that membrane tension has on lateral module stiffness for several assumed boundary conditions associated with either single- or doublestretched membrane modules. As such, the model should be valuable in sizing and design trade-offs, in establishing trends, and in developing understanding of the various stretched membrane response mechanisms and their interactions. To this end a much more extensive analysis of varlous trade-offs using this model will be forthcoming.

A note of caution is approprlate here. As with any model, care should be exercised in Its use, particularly to ensure that the inherent assumptions are consistent with the real problem being analyzed.

The analysis approach developed here is quite amenable to modifications, which can account for varlous response mechanisms such as different frame support boundary conditions that have not been considered in the current model. We recommend that these extensions be developed as the need for such information is demonstrated. 
TABLE OF CONTENTS

$\underline{\text { Page }}$

1.0 Introduction. ...................................... 1

2.0 Model Assumptions.................................. 3

3.0 Variational Methodology............................. 7

3.1 Frame Bending Strain Energy......................... 8

3.2 Frame Twist Strain Energy.......................... 9

3.3 Membrane Strain Energy............................ 9

3.4 Body Forces and Applied Loads......................... 10

4.0 The Solution Approach.............................. 12

5.0 Model Results................................... 15

6.0 Conclusions....................................... 21

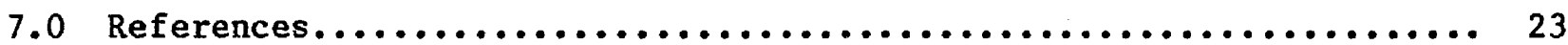

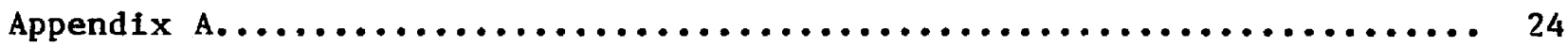

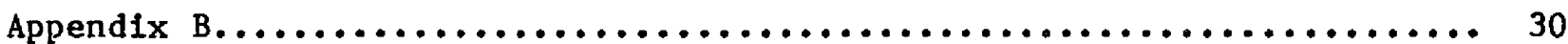

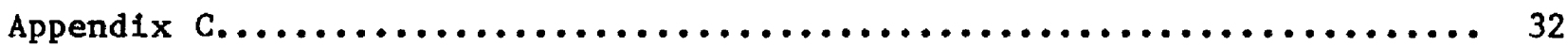

Appendix D.......................................... 40

Appendix E.......................................... 42

Distribution List.................................... 44 


\title{
LIST OF FIGURES
}

\begin{abstract}
2-1 Idealized Stretched Membrane Reflective Module................ 4
2-2 Frame and Membrane Cross-Section Details for Either Single- or Double-Membrane Designs................................ 5

5-1 Assumed Geometry and Loading on Modules Considered In Discussion of Results........................................ 17

5-2 Flexural and Torsional Rigidity of Steel Frame Section as a Function of Frame Half Height.......................... 18

5-3 Maximum Frame Deflection as a Function of Frame Half Height for Design Cases 1,2 , and $3 \ldots \ldots \ldots \ldots \ldots \ldots \ldots \ldots \ldots \ldots \ldots \ldots \ldots \ldots \ldots$

5-4 Frame Deflection and Twist as a Function of Angular Distance between the Supports for Case 2........................... 19

B-1 Axisymmetric and Nonsymmetric Deformation Patterns Caused by Lateral Loading and Support Constraints.....................
\end{abstract}

Page

\section{LIST OF TABLES}

5-1 Example Results Comparing NASTRAN Predictions with the Current Mode1...................................... 16

A-1 In-Plane Membrane Response Results........................ 27

E-1 Membrane Stiffness Coefficients......................... 43 


\section{NOMENCLATURE}

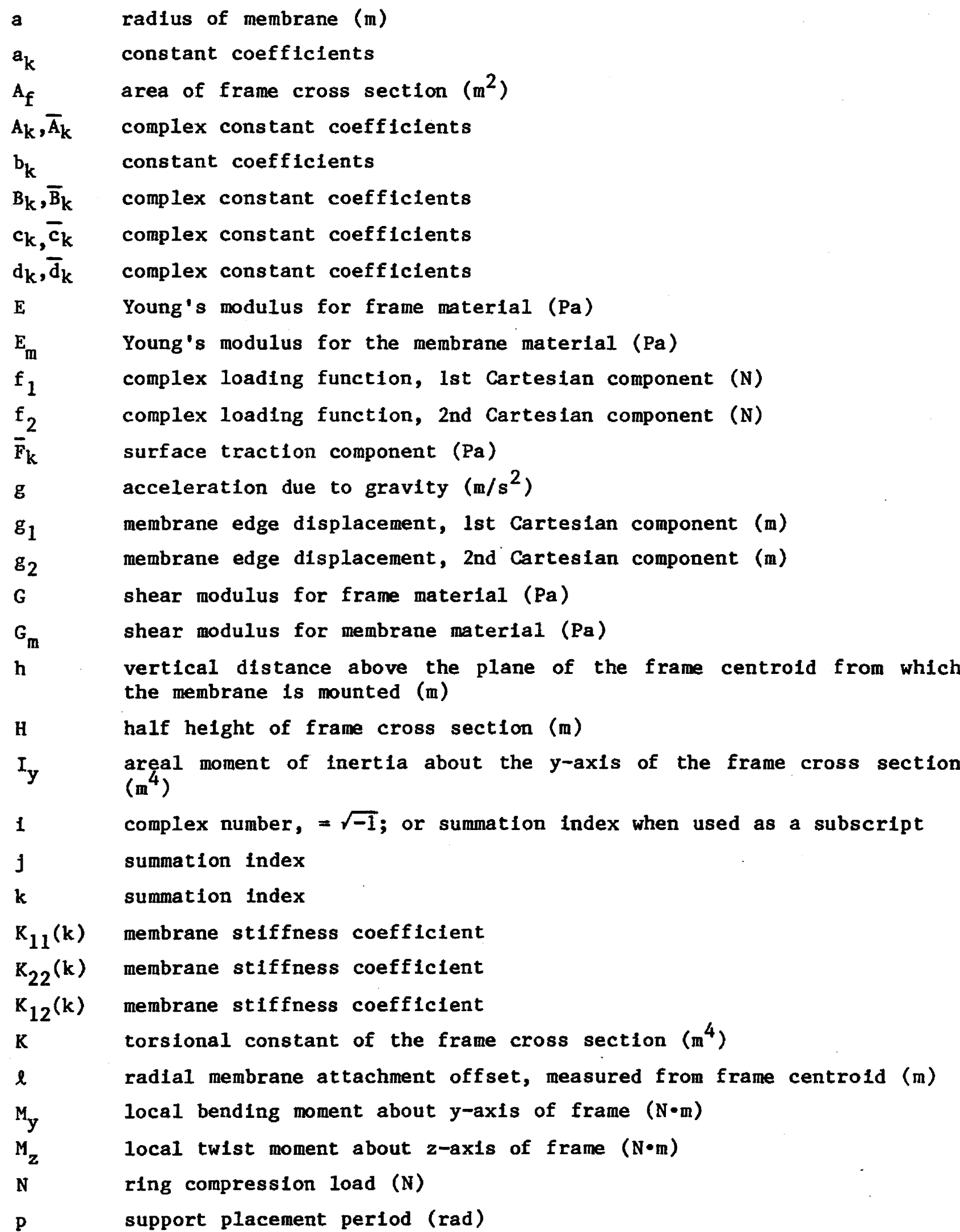




\section{MOMENCLATURE（Continued）}

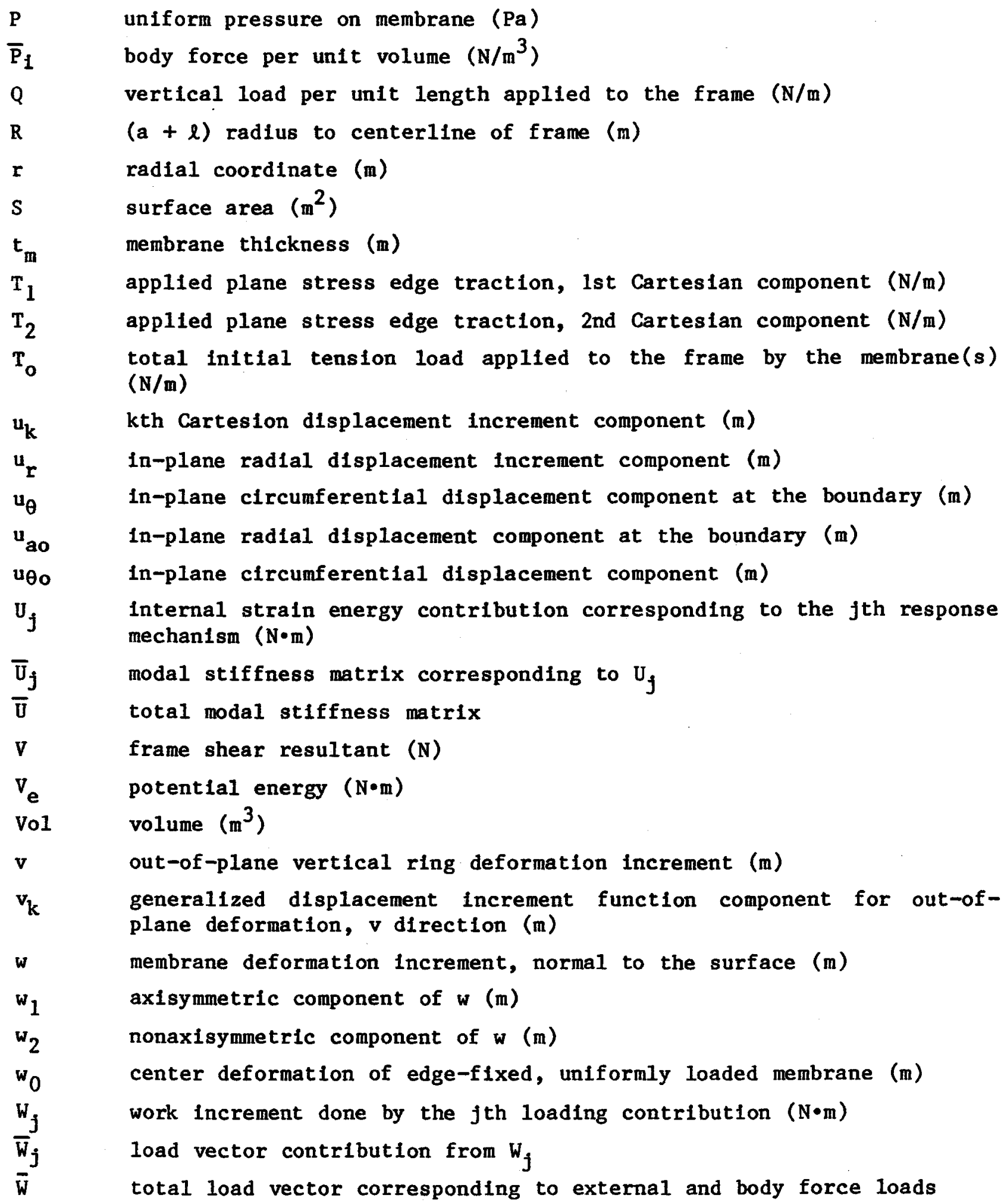




\begin{abstract}
MOMENCLATURE (Continued)
$x, y, z \quad$ local coordinates measured from the centroid of an arbitrary circumferential $(\theta)$ frame cross section; $x$ is directed vertically upward and is normal to the membrane plane; $y$ is directed radially outward and is parailel to the membrane plane; $z$ is circumferentially directed (normal to the cross-section plane) in the positive $\theta$ direction

$\mathbf{Z}$

complex variable
\end{abstract}

\title{
Greek symbols
}

$\alpha \quad=-\left.\frac{\partial w}{\partial r}\right|_{r=a}=$ angle with which the membrane meets the frame measured from the horizontal (rad)

$\beta \quad$ total rms membrane surface slope error (rad)

$\beta_{1}$ rms surface slope error corresponding to $w_{1}$ (rad)

$\beta_{2} \quad$ rms surface slope error corresponding to $w_{2}$ (rad)

$\theta \quad$ circumferential coordinate (rad)

$\Delta \mathrm{T}_{\mathrm{o}} \quad$ in-plane tension increment applied at the membrane boundary $(\mathrm{N} / \mathrm{m})$

$\Delta S_{0}$

$\gamma$ in-plane shear increment applied at the membrane boundary $(\mathrm{N} / \mathrm{m})$ the angle between the normal to the membrane and the gravity vector $(\mathrm{rad}) ; \leqslant \pi / 2$

$\Gamma \quad=\frac{3-v_{m}}{1+v_{m}}$ for plane stress

$\varepsilon_{\mathrm{kj}} \quad$ strain increment tensor

$v_{m}$

Poisson ratio of membrane

$=1$ for $k=0$

$\eta_{k} \quad=1 / 2$ for $k \neq 0$

$\rho_{\mathbf{f}}$

density of frame material $\left(\mathrm{kg} / \mathrm{m}^{3}\right)$

$\rho_{\mathrm{m}}$ density of membrane material $\left(\mathrm{kg} / \mathrm{m}^{3}\right)$

$\lambda$ displacement coefficient vector

$\xi$ angular integration variable (rad)

$\Phi(Z) \quad$ analytic function for the plane stress problem

$\Psi(Z) \quad$ analytic function for the plane stress problem

local surface rotation vector for the membrane (rad)

$\phi \quad$ frame twist increment angle (rad)

$\phi_{k}$ displacement function components, $\phi$ direction (rad)

$\sigma_{k j} \quad$ stress increment tensor ( $\mathrm{Pa}$ )

$\sigma_{\mathbf{k j}}$

$\tau_{\mathbf{r r}}$

initial state stress tensor ( $\mathrm{Pa})$

radial stress component in membrane $(\mathrm{Pa})$ 
MOMENCLATURE (Concluded)

$\tau_{\theta \theta} \quad$ circumferential stress component in membrane (Pa)

$\tau_{\mathrm{r} \theta} \quad$ shear stress component in membrane (Pa)

( )' a prime superscript denotes differentiation with respect to $\theta$ 
SECTION 1.0

\section{INTRODUCTION}

The structural response of a stretched membrane frame combination supported by periodic attachments located at equidistant points on the circumference and subjected to uniform pressure loads normal to the plane of the membrane is the problem studied in this report. This problem is of interest in the design, evaluation, and optimization of stretched membrane heliostats, which have been a research focus for some time (Murphy 1983).* Some aspects of this problem also occuring in single-membrane designs were analyzed in an earlier report (Murphy and Sallis 1984) where a direct equilibrium approach and a simple iterative numerical integration procedure were found to predict deformations and internal loads quite close to those predicted by the NASTRAN (Schaeffer 1979) structural computer code. The approach taken here is different in that a variational approach, which yields the appropriate equilibrium equations, is used to provide an approximate but accurate description of the load deformation response.

The variationai principle developed here uses the concept of potential energy and employs the Rayleigh Ritz procedure [see, for example, Thompson and Hunt (1984)] where a compatible set of displacement functions (or shape functions) describes the displacements within the domain of interest. In this procedure each of the displacement functions must independently satisfy the boundary conditions, and the set of compatible shape functions forms a set of generalized coordinates. The resulting variational principle can then be expressed in terms of these generalized coordinates and will yield the desired solution by minimizing the resulting functional where an arbitrary variation on the constant coefficients multiplying the shape functions is performed.

The approach taken here is to formulate the functional to be varied as a function of state vectors, the components of which are the generalized coordinates, which results in a stiffness matrix similar to that done in the finite element procedure.

We selected a variational approach rather than extend the direct equilibrium approach as developed in Murphy and Sallis (1984). Th1s approach allows somewhat easier implementation of various response considerations, such as multiple membrane effects, the in-plane response of the membrane, and the impact of different attachment approaches. The approach also permits relatively easy quantification and isolation of the various separate response mechanisms when compared with the more comprehensive NASTRAN analysis approach (Schaeffer 1979). This occurs because the relevant deformation pattern for the frame can be readily deduced and accurately expressed as simple displacement functions, and because the in-plane membrane response can be determined by classical methods. Further, the general approach is easily extended to address other response issues not explicitly considered here, such

*Sandia National Laboratories at Livermore is currently directing the development of the concept, including the design and fabrication of largescale prototype modules. 
as the in-plane stiffness response of the frame. The resulting computational requirements using this approach are also much simpler and less costly to implement than with the iterative direct integration approach. 


\section{SECTION 2.0}

\section{MODEL ASSUMPTIONS}

Consider a clrcular stretched membrane reflector support frame assembly as shown in Figures $2-1$ and 2-2, and let the following assumptions hold:

- Consideration of single- or double-membrane concepts is allowed. Singlemembrane concepts may have the membrane attached at an arbitrary unfform helght $h$ vertically above the plane passing through the centrold of the toroidal frame. Double membranes are assumed to be placed symmetrically at th with respect to the centroid plane, and the inftial tension in each of the membranes is assumed to be exactly equal to one half of the total tension load (see Figure 2-2).

- The toroldal frame of mean radius $R$ on which the membrane( $s$ ) is (are) stretched is supported vertically at any number of equidistant points around the circumference. However, the analysis results presented here correspond to only three support points. These constraints approximate the reactions of a tripod support strut arrangement similar to that found in some hellostat designs (Murphy 1983).

- The frame supports offer constraint only perpendicular to the plane of the membrane; 1.e., the frame is free to rotate at the supports but not free to translate vertically. There is no constraint in the radial direction.

- The principle of linear superposition is assumed to be valid for both the deformation and the stress states in the frame and membrane. Thus, deformations and stresses caused by the pressure and weight loads applied normal to the membrane are superimposed on the initial prestressed and prestrained state implied by the inftial membrane tension state. Zero inftial deformation normal to the plane of the membrane is assumed for the frame. In the case of double-membrane designs, initial axisymmetric and self-equilibrating out-of-plane membrane deformations corresponding to a partial vacuum between the membrane are permissible.

- Small strain, large out-of-plane displacement theory is assumed for both the frame and membrane.

- With respect to the membrane:

- The membrane has in-plane stiffness but no bending stiffness and carries loads only in tension. Thus changes in the geometric configuration of the surface are required to support loads normal to the membrane surface.

- The out-of-plane membrane deformations are assumed to cause negligible load increments in the average membrane tension.

- In-plane membrane deformations are small and the corresponding tension increments are assumed to be small with respect to the membrane pretension and to be induced by one of two mechanisms; either through limiting the rotations of the frame or by participating in the out-ofplane bending of the frame with a fixed attachment (this last 


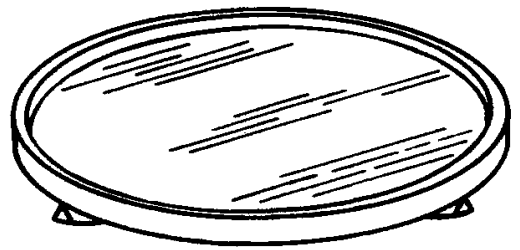

(a) Perspective view - stretched-membrane reflective module; pin supported at three equidistant circumferential points

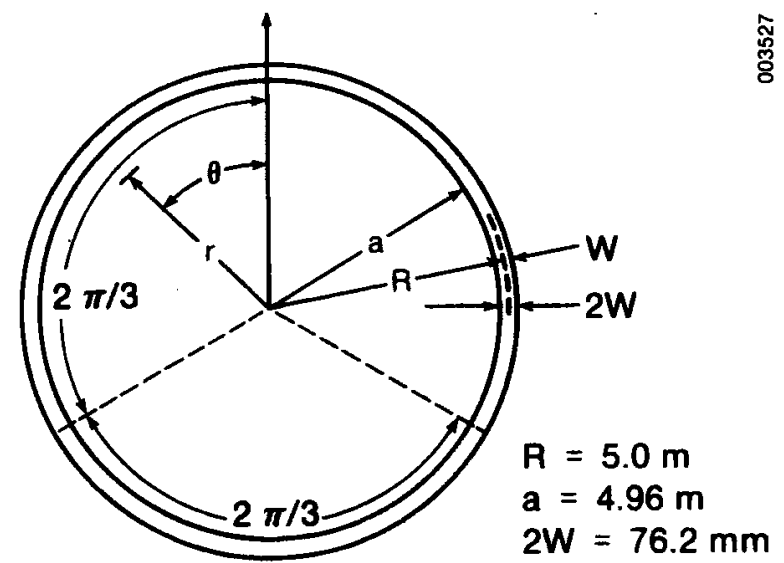

(b) Top view - streiched-membrane reflectlve module

\section{Figure 2-1. Idealized Stretched Membrane Reflective Module}

mechanism is akin to the membrane providing an additional flange on the frame). Thus, in-plane and out-of-plane membrane deformations and tension increments are coupled only through the frame.

- Only out-of-plane deformation and twist increments of the ring are considered (radial shear and radial ring deformations are ignored).* Circumferential compressive loads in the support frame are important, as are the normally considered twist, vertical shear, and moment resultants. The coupling of the out-of-plane deformation with the compressive force in the ring must be considered, but that compression force is assumed to remain constant around the circumference in all cases.

*The radial deformation of the frame consistent with the membrane pre-tension Is assumed to have occurred prior to application of the load normal to the plane of the membrane. Note that this radial deformation caused by the membrane pre-tension can be of the same order of magnitude as subsequent outof-plane deformations. 


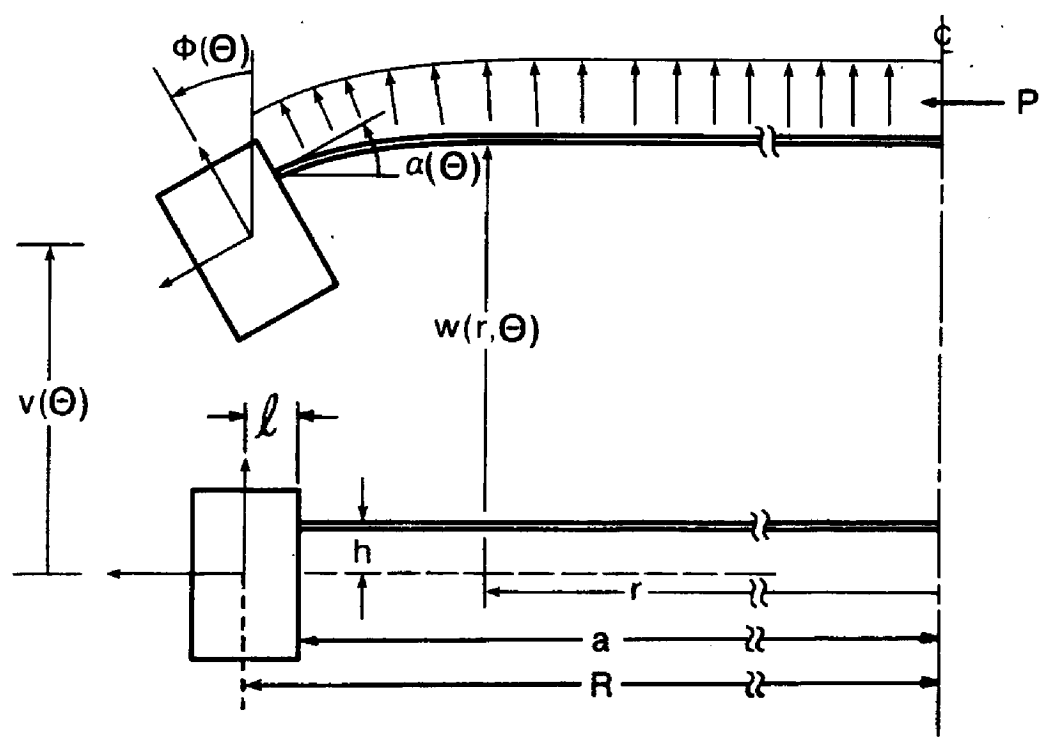

(a) Frame and cross-section detail showing displacements and the corresponding directions and applied loading for a single membrane module. The membrane is uniformly loaded with a pressure $P$.

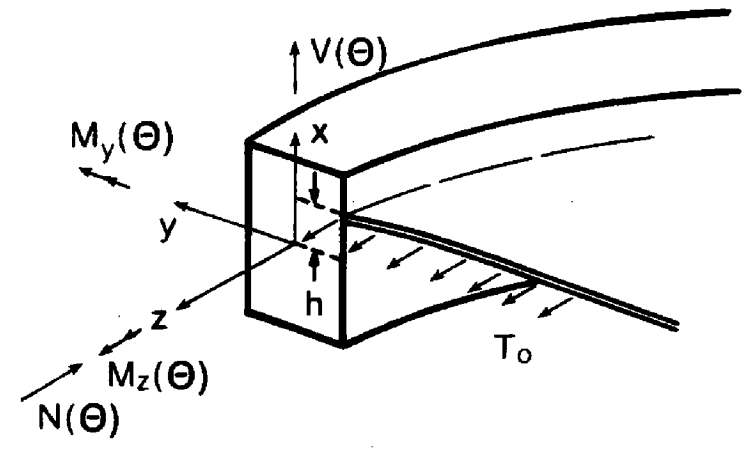

Single membrane

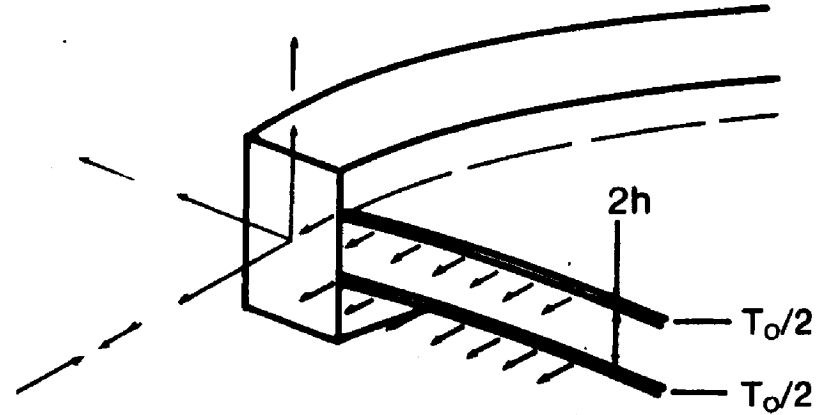

Double membrane

(b) Perspective of frame and membrane cross section showing internal load resultants and local coordinates

Figure 2-2. Frame and Membrane Cross-Section Detalls for Either Singleor Double-Menbrane Designs 
- The frame cross section is assumed to be symmetric about the plane, which is parallel to the membrane and passes through the shear center of the frame.*

- Displacement compatibility of the membrane at the support frame interface attachment is required.

- The pressure loading is assumed to be uniform over the membrane surface. In the case of two membrane concepts, half of the pressure distribution is applied to each membrane (see Figure 5-1). This last assumption is consistent to a first approximation, with fundings from wind-loading studies.

- Weight effects, which act normal to the nominal plane of the membrane, are considered.

*Nonsymmetric cross sections with products of inertia other than zero lead to more coupling terms than appear in the equations below. 
SECTION 3.0

VARLATIONAL METHODOLOGY AND MODEL DESCRIPTION

Before the stretched membrane module was subjected to lateral wind or welght loads, it was prestressed by tensioning the membrane. This tensioning induced an initial state of compressive stress and deformation in the body (membrane/frame assembly), and any additional stress and deformation increments caused by external loading must be added to determine the final state of stress and deformation in the body. The appropriate variational principle based on the concept of virtual work for such bodies subjected to an Initlal state of stress can be defined as in Washizu (1982) by

$$
\int_{V o l}\left(\sigma_{i j} \delta \varepsilon_{1 j}+\sigma_{1 j}^{0} u_{k, i} \delta u_{k, i}-\bar{P}_{i} \delta u_{i}\right) d V o 1-\int_{S} \bar{F}_{i} \delta u_{i} d S=0,
$$

where $\sigma_{1 j}, \varepsilon_{i j}$, and $u_{k}$ denote the Cartesian tensor increments in stress, strain, and displacement components, respectively, relative to the existing stress and deformation state within the volume Vol. The term $\sigma_{1 j}^{o}$ represents the current state of stress within the body prior to the application of the incremental body force per unit volume $\bar{P}_{\mathcal{I}}$ and the incremental surface traction per unit area $\bar{F}_{1}$ on the surface $S$. The term $\delta$ denotes an arbitrary variation of the quantity following it, constrained only by compatibility requirements. Physically, the term involving $\sigma_{1 j}^{0}$ denotes the work done by the existing internal prestresses as the body experiences the displacement increment field corresponding to $u_{1}$. This term involving $\sigma_{1 j}$ gives rise to what is sometimes called the geometric stiffness effect, which results from the change in direction of the internal forces caused by the distortion of the structural element under consideration. Both $\bar{P}_{1}$ and $\bar{F}_{1}$ are assumed to be prescribed quantities. For these conditions and for elastic systems an appropriate energy potential can be written as

$$
v_{e}=\frac{1}{2} \int_{V o l}\left(\sigma_{i j} \varepsilon_{1 j}+\sigma_{1 j} u_{k, i} u_{k, j}-\bar{P}_{1} u_{i}\right) d V_{o l}-\int_{S} \bar{F}_{1} u_{i} d S .
$$

Further, for lineartzed problems the contributions of various response mechanisms (e.g., beam bending, twist, membrane rotation) and the applied loads can be linearly superimposed, so the potential can be described by

$$
v_{e}=\sum_{1}^{6} u_{j}-\sum_{1}^{3} w_{j},
$$

where $U_{j}$ corresponds to the internal strain energy increment of the $j$ th response mechanism. The term $W_{j}$ corresponds to work done by the $f$ th external or body load increment. Both $U_{j}$ and $W_{j}$ are defined later in this section.

The potential $V_{e}$ can be specialized for the corresponding particular configuration of the circular stretched membrane module as described in Figure 2-1. Let the displacement increments, which correspond to the 
prescribed wind and weight load increments, be defined as illustrated in Figure 2-2. Then consider the frame bending, frame torsion, and membrane response in succession, followed by a description of the prescribed wind and weight load increments according to the problem assumptions defined above. The appropriate contribution to the potential energy (Eq. 3-3) from each of response mechanisms and loads follows. More specifically, we describe each contribution to the energy potential in Eq. 3-3 in terms of the frame displacement $\sigma$ and the frame rotation $\phi$.

\subsection{FRAME BENDING STRAIN GNERGY}

The strain energy for the ring undergoing out-of-plane bending stralns caused by the bending moment $M_{y}$ is given by

$$
U_{1}=\frac{R}{2} \int \frac{M_{y}^{2}}{E I_{y}} d \theta=\frac{E I_{y}}{2 R} \int\left(\frac{v^{\prime \prime}}{R}-\phi\right)^{2} d \theta,
$$

where $v$ and $\phi$ are the lateral and rotational displacement increments of the frame as defined in Figure 2-2 and where the moment-curvature relationship (Murphy and Sallis 1984; Meek 1969), in terms of the displacement increments v and $\phi$, is given by

$$
M_{y}=\frac{E I_{y}}{R}\left(\frac{v^{\cdots \cdot}}{R}-\phi\right)
$$

The term $R$ is the mean frame radius, $E$ is Young's modulus for the frame, and $I_{y}$ corresponds to the moment of inertia of the frame cross section about the local y-axis.

Further, the ring under compression (of amount $T_{0} a$ ) by virtue of the membrane pre-tension $\left(T_{0}\right) *$ provides a geometric distortion contribution to the internal strain energy. This is because the compressive load does internal work as the deformation increments $v$ and $\phi$ proceed. The magnitude of this effect is given by

$$
\mathrm{U}_{2}=-\frac{\mathrm{T}_{\mathrm{o}} \mathrm{a}}{2 \mathrm{R}} \int \mathrm{v}^{\prime} 2 \mathrm{~d} \theta
$$

where $a$ is the mean radius of the membrane that differs from $R$ by an amount $l$ (see Figure 2-2). This effect is exactly analogous to the lateral distortion effect in an axlally compressed simple beam undergoing prebuckling deformation (Timoshenko and Gere 1961).

\footnotetext{
*It is important to note that the membrane tension $T_{0}$ corresponds to the total tension load applied to the frame by the membrane( $\mathrm{s}$ ). If two membranes are employed, then the inftial tension in each membrane is assumed to be $T_{0} / 2$.
} 


\subsection{FRAME TWIST STRAIN ENERGY}

Twisting of the frame caused by a local twist moment $M_{z}$ results in a strain energy contribution of

$$
\mathrm{U}_{3}=\frac{\mathrm{R}}{2} \int \frac{\mathrm{M}_{\mathrm{z}}{ }^{2}}{\mathrm{GK}} \mathrm{d} \theta=\frac{\mathrm{GK}}{2 \mathrm{R}} \int\left(\frac{\mathrm{v}^{\prime}}{\mathrm{R}}+\phi^{\prime}\right)^{2} \mathrm{~d} \theta,
$$

where we used the moment-twist relation,

$$
M_{z}=\frac{G K}{R}\left(\frac{v^{\prime}}{R}+\phi^{\prime}\right)
$$

as derived in Murphy and Sal1is (1984) and Meek (1969). The terms G and K correspond to the frame material shear modulus and torsional constant, respectively.

In addition, as the frame twists there is a geometric internal strain energy contribution of

$$
\mathrm{U}_{4}=\frac{\mathrm{T}_{\mathrm{o}} \mathrm{al}}{2} \int \phi^{2} \mathrm{~d} \theta
$$

which accrues as the frame attachment point is rotated out of its original plane by the offset arm of length $\ell$.

\subsection{MEMBRANE STRAIN ENERGY}

We assumed earlier that out-of-plane membrane deformation does not induce membrane tension increments but that in-plane tension increments can be Induced by the frame deformations. This allows us to describe the membrane strain energy using decoupled contributions from the in-plane and out-of-plane response.

The elastic strain energy in a membrane caused by in-plane strain increments can be related to the displacements and stresses at the attachment by the following relationship,

$$
\mathrm{u}_{5}=\frac{a t_{\mathrm{m}}}{2} \int\left[\tau_{\mathrm{rr}}(\mathrm{a}, \theta) \mathrm{u}_{\mathrm{ao}}+\tau_{\mathrm{r} \theta}(\mathrm{a}, \theta) \mathrm{u}_{\theta \mathrm{o}}\right] \mathrm{d} \theta,
$$

where $t_{m}$ is the membrane thickness and $\tau_{r r}(a, \theta)$ and $\tau_{r}(a, \theta)$ are the radial and circumferential tractions, respectively, applied to the circular boundary of the membrane. The form for $U_{5}$, which is analogous to that of a simple spring, is developed in Appendix $A$; the displacements $u_{a o}$ and $u_{\theta o}$ are related to $v$ and $\phi$ by compatibility requirements of the frame at the attachment and by the boundary conditions. The resulting definitions hold

$$
\mathbf{u}_{\mathrm{ao}}=\mathrm{h} \phi
$$


and

$$
\mathrm{u}_{\theta 0}=\frac{-\mathrm{ah}}{\mathrm{R}^{2}} \mathbf{v}^{\prime}
$$

Appendix A provides an appropriate description for $U_{5}$ corresponding to elther a simple radial attachment or a hard (bond or weld) attachment.

Consider now the strain energy increment caused by out-of-plane deformations. The internal increase in membrane strain energy caused by the work done by the initial preload $\mathrm{T}_{0}$ (assumed to be constant) during lateral deformation of the membrane is given by

$$
U_{6}=\frac{T_{0}}{2} \iint_{S}\left(w^{2}, r+\left(\frac{1}{r} w, \theta\right)^{2}\right) r d r d \theta
$$

where $w, r$ and $\frac{1}{r} w, \theta$ are the local surface derivatives on the membrane surface.

With respect to Eq. 3-13, two items are worthy of note. F1rst, Eq. 3-13 represents the classical strain energy normally considered for a membrane attached to a rigid support. Second, note that no material stiffness constants are present, and the membrane supports the load only by out-of-plane distortions. Hence, this strain energy in this case corresponds solely to the geometric effect discussed earlier. Note also that the sign of $U_{6}$ is positive; hence, as the membrane deforms, the stiffness to lateral loading increases.

Murphy and Sal1is (1984) showed that the membrane deformation problem under the constant tension assumption can be further defined by considering the superimposed solutions corresponding to two independent boundary value problems. One corresponds to a homogeneous boundary condition with the applied uniform load, and one corresponds to the nonhomogeneous boundary condition but with no load normal to the membrane. This same kind of decomposition can be used to describe the values of $w, r$ and $\frac{1}{r} w, \theta$ in terms of the edge displacements (at the frame) plus a term corresponding to the membrane deformation when the boundary is fixed (see Appendix B). Further, this decomposition will hold only when the mean tension on the membrane is constant or nearly so.

\subsection{BODY FORCES AND APPLIED LOADS}

The body force increment terms used to account for the work done by the normal component of gravity loading on the frame $\left(W_{1}\right)$ and on the membrane $\left(W_{2}\right)$ are defined by

$$
W_{1}=\rho_{f} A_{f g} R \cos \gamma \int v d \theta
$$

and

$$
W_{2}=\rho_{m} t_{m} g \cos \gamma \int_{S} w r d r d \theta
$$


where

$\rho_{f}$ and $\rho_{m}=$ the density of the frame and membrane materials,

$A_{f}=$ the frame cross section area

$t_{m}=$ the thickness of the membrane

$\mathrm{g}=$ the acceleration caused by gravity

$\gamma=$ angle between the gravity vector and the vector that is perpendicular to the plane of the frame.

The work $\left(W_{3}\right)$ done by the external pressure loading increment $P$ (assumed to be caused by the wind component, which is normal to the plane of the membrane) is given by

$$
W_{3}=P \int w r d r
$$

Equations 3-4 through 3-16 and Appendices $A$ and $B$ allow us to describe the potential energy totally with the frame displacements. The solution follows in the next section. Before proceeding, note that when an arbitrary variation on the displacement in Eqs. 3-4, 3-6,3-7, 3-9, 3-13, and 3-16 is performed, we get the equilibrium equations as derived by the direct method in Murphy and Sallis (1984) for the center-mounted single-membrane concept. 
SECTION 4.0

THE SOLUTION APPROACH

The solution for the displacements results from minimizing the total potential energy Eq. 3-3 with Eqs. 3-4 through 3-16 and with an assumed form for the displacement increment functions corresponding to $v$ and $\phi$. To this end $v$ and $\phi$ are taken to be of the form

$$
v=\sum_{k=1}^{m} a_{k} v_{k}(\theta)=v(\theta)
$$

and

$$
\phi=\sum_{k=0}^{m} b_{k} \phi_{k}(\theta)=\phi(\theta),
$$

where $a_{k}$ and $b_{k}$ are constant coefficients to be determined by the minimization process and where $v_{k}(\theta)$ and $\phi_{k}(\theta)$ are a compatible set of displacement increment functions satisfying the boundary conditions. The term $m$ is an arbitrary integer selected to attain the degree of accuracy desired. The boundary conditions, which are assumed to govern the problem, are similar to those discussed and used in Murphy and Sallis (1984).* These conditions correspond to zero out-of-plane displacement of the frame at the supports and to deformation symmetry of both the frame and membrane about the supports, which are assumed to be uniformly spaced at an angular interval p. Thus, the boundary conditions are written

$$
v(0)=v(p)=v^{\prime}(0)=v^{\prime}(p)=\phi^{\prime}(p)=\phi^{\prime}(0)=0 .
$$

Then, with these boundary conditions we chose the form for the displacement functions to be

$$
v_{k}(\theta)=1-\cos \frac{2 \pi k}{p} \theta ; \quad k=1, \ldots m
$$

and

$$
\phi_{\mathrm{k}}(\theta)=\cos \frac{2 \pi \mathrm{k}}{\mathrm{p}} \theta ; \quad \mathrm{k}=0,1, \ldots . \mathrm{m}
$$

It is also demonstrated in Appendices $A$ and $B$ that both the in-plane and outof-plane membrane deformations are governed by the frame displacement coefficients $a_{k}(k=1, \ldots . m)$ and $b_{k}(k=0,1, \ldots . m)$ defined in Eqs. 4-1

* Note that there is no term corresponding to $k=0$ in Eq. 4-1 since this would correspond to a rigid body translation. On the other hand, a uniform twist of the frame is possible; hence, there is a term corresponding to $k=0$ in Eq. 4-2. 
and 4-2 and one other displacement function corresponding to the axisymmetric lateral membrane deformation $w_{1}$, induced by the uniform pressure increment. The term $\mathrm{w}_{1}$ takes the form

$$
w_{1}=a_{0}\left[1-\left(\frac{r}{a}\right)^{2}\right] \text {. }
$$

Having defined the necessarly displacement functions (or generalized coordinates), the problem is now reduced to finding the appropriate values of the spatially constant coefficients $a_{k}$ and $b_{k}(k=0,1, \ldots$. . m) to minimize the potential energy given by Eq. $3-3$ for a given set of load and body force increments. This is accomplished in the following manner.

First, express Eq. $3-3$ as a single displacement coefficlent vector $\lambda$ defined by

$$
\lambda^{T}=\left[a_{0}, a_{1}, \ldots a_{m}, b_{0}, b_{1} \ldots . b_{m}\right] .
$$

Using this formalism, $V_{e}$ can then be written as

$$
\mathrm{V}_{\mathrm{e}}=\frac{1}{2} \lambda^{\mathrm{T}} \overline{\mathrm{U}} \lambda-\lambda^{\mathrm{T}} \mathrm{W}
$$

where $\bar{U}$ is a $(2 m+2 \times 2 m+2)$ symmetrical matrix with a contribution from Eqs. $3-4,3-6,3-7,3-9,3-10$, and $3-13$, and where $\bar{W}$ is a $(2 m+2 \times 1)$ column vector with contributions from Eqs. 3-14, 3-15, and 3-16.

Thus, when comparing Eq. 4-8 with Eq. 3-3, we see that

$$
\frac{1}{2} \lambda^{\mathrm{T}} \overline{\mathrm{U}} \lambda=\sum_{j=1}^{6} \mathrm{U}_{j}=\frac{1}{2} \lambda^{\mathrm{T}}\left(\sum \overline{\mathrm{U}}_{\mathrm{j}}\right) \lambda
$$

and

where

$$
\lambda^{T} \bar{W}=\sum_{j=1}^{3} W_{j}=\lambda^{T}\left(\sum_{j=1}^{3} \bar{w}_{j}\right),
$$

$$
\bar{U}=\sum_{j=1}^{6} \overline{\mathrm{U}}_{\mathbf{j}}
$$

and

$$
\bar{W}=\sum_{j=1}^{3} \bar{W}_{j}
$$

The terms $\bar{U}$ and $\bar{W}$ physically represent the modal stiffness matrix and modal load vector corresponding to the selected generalized coordinate functions, Eqs. 4-4 through 4-6. The matrix $\bar{U}_{j}$ and vector component $\bar{W}_{j}$ contributions to $\bar{U}$ and $\bar{W}$ are defined in Appendix $C$ for the selected generalized coordinates and for the assumed attachment conditions. 
By minimizing $v_{e}$ with respect to $\lambda$ in Eq. 4-8, we determine $\lambda$; thus

$$
\frac{\partial V_{e}}{\partial \lambda}=0=\bar{U} \lambda-\bar{W}=0 \text {, }
$$

which results in

$$
\lambda=(\bar{U})^{-1} \bar{W}
$$

where $(\bar{U})^{-1}$ is defined as the matrix inverse of $\bar{U}$.

Several appendices are provided. Appendix A provides a detalled description of the in-plane membrane response corresponding to elther prescribed edge tractions or edge deformations for the membrane. The derived solutions are then related to the desired membrane attachment boundary conditions, and the contribution to the $\overline{\mathrm{U}}$ matrix from the corresponding membrane response is then determined. Appendix $B$ provides a description of the out-of-plane membrane deformation as a function of the frame displacements and the pressure loading. Appendix $C$ provides a detailed description of the specific contributions to the $\bar{U}$ matrix from all of the response mechanisms considered in terms of geometric and material properties corresponding to specific design options for double-membrane modules. Thus, to implement the solution presented here we need only use Appendix $C$ with Eqs. 4-1 through 4-3 and 4-14 along with the desired input parameters. Appendix $D$ provides a short description of other useful quantities such as the total rms surface error and the stress state in the membrane at the attachment in terms of the solution vector. Appendix $\mathrm{E}$ gives an even simpler approximate solution based on assuming only two displacement functions (one for $v$ and one for $\phi$ ), which can be used for first order design trade-offs and for eigenvalue stability analyses. The approximations are useful when studying the effects of initial imperfection and the amplification of load-induced, out-of-plane deformation. 


\title{
SECTION 5.0
}

\author{
MODEL RESULTS
}

In this section we briefly compare results from the current model with predictions from the NASTRAN computer model. The NASTRAN model was implemented in the general nonlinear mode and was 1imited primarily by the frame support and bonding assumptions. In other words, most of the assumptions, such as no net radial deformation increments of the frame and the assumptions of linearity, are not employed in the NASTRAN model. The good agreement, which will be demonstrated, thus demonstrates the validity of the model assumptions for the range of parameters considered. The results shown here correspond to three separate module design approaches composed of two double-membrane designs and one single-membrane design as shown in Figure 5-1. In the double-membrane design we consider either a radial-only constraint or a radial and circumferential (hard) attachment constraint. We looked at two different tensions and considered the effects of two materials (steel and aluminum). We also considered the predictions for a range of frame section parameters. In addition to the geometry of single- and doublemembrane designs lllustrated in Figure 5-1a, the loading for the cases considered, and assumed to be induced by pressure (due to wind) and weight loading, is defined in Figure 5-1b.

We will consider four deslgn cases. Design Case 1 corresponds to the singlemembrane design. Design Case 2 is a double-membrane design with a radial-only attachment. Design Case 3 corresponds to a double-membrane design with the hard or totally fixed attachment. Design Cases 1, 2, and 3 are all assumed to be fabricated with steel membranes and steel frame sections. Design Case 4 is similar to Case 3 but with aluminum membranes and aluminum frame materfal instead of steel.

Figure 5-2 shows the effect of section height on the flexural and torsional rigidity for a steel frame of the design shown in the inset (Figure 5-2). These respective frame section properties were used in the deformation predictions corresponding to Cases 1, 2, and 3 shown in Figure 5-3.

Figure 5-3 shows the maximum deflection of the frame versus half height of the frame for the loading and geometry shown in Figure 5-1 for Design Cases 1, 2, and 3 and for a tension of $17,500 \mathrm{~N} / \mathrm{m}(100 \mathrm{lb} / \mathrm{in}$.$) . Here, we can see the$ strong effect of section flexural rigidity; i.e., corresponding to a change in the frame half height. This figure illustrates the kind of varlation one experiences by changing the frame design. For comparison, the NASTRAN numerical modeling results are shown for specific cases, and we can see that quite good agreement does occur for the cases investigated. This good agreement is also seen in Table 5-1, where the numerical results for Cases 1 through 4 are compared for two tensions and two frame heights. The maximum displacement $v_{\text {max }}$ corresponds to the predicted peak deflection experienced midway between the support, and $\phi$ corresponds to the frame rotation that occurs at the same location as $v_{\max }$ 
Table 5-1. Example Results Comparing MASTran Predictions with the Current Model

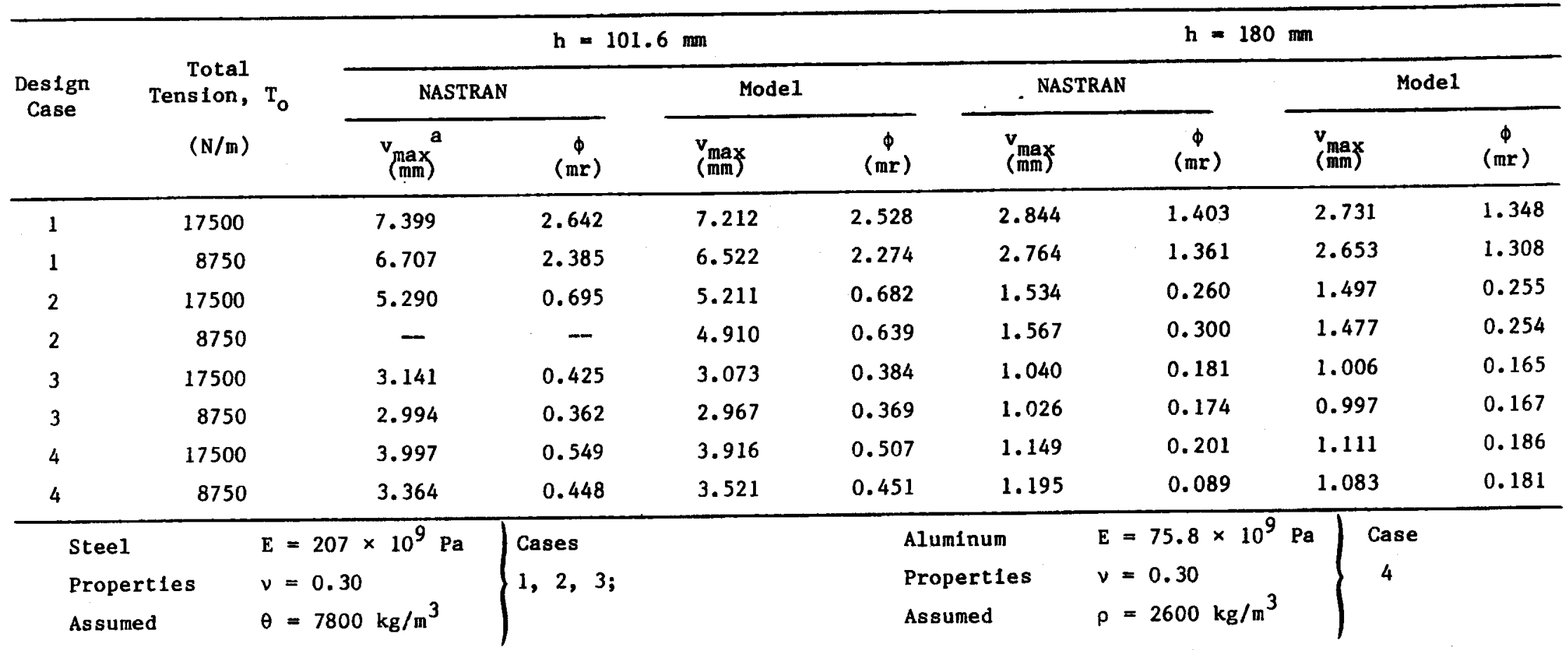

${ }^{a} v_{\text {max }}$, corresponds to the maximum displacement, midway between the support (1.e., at $\theta=60^{\circ}$ ); $\phi$ is measured at the same location as $v_{\max }$ 


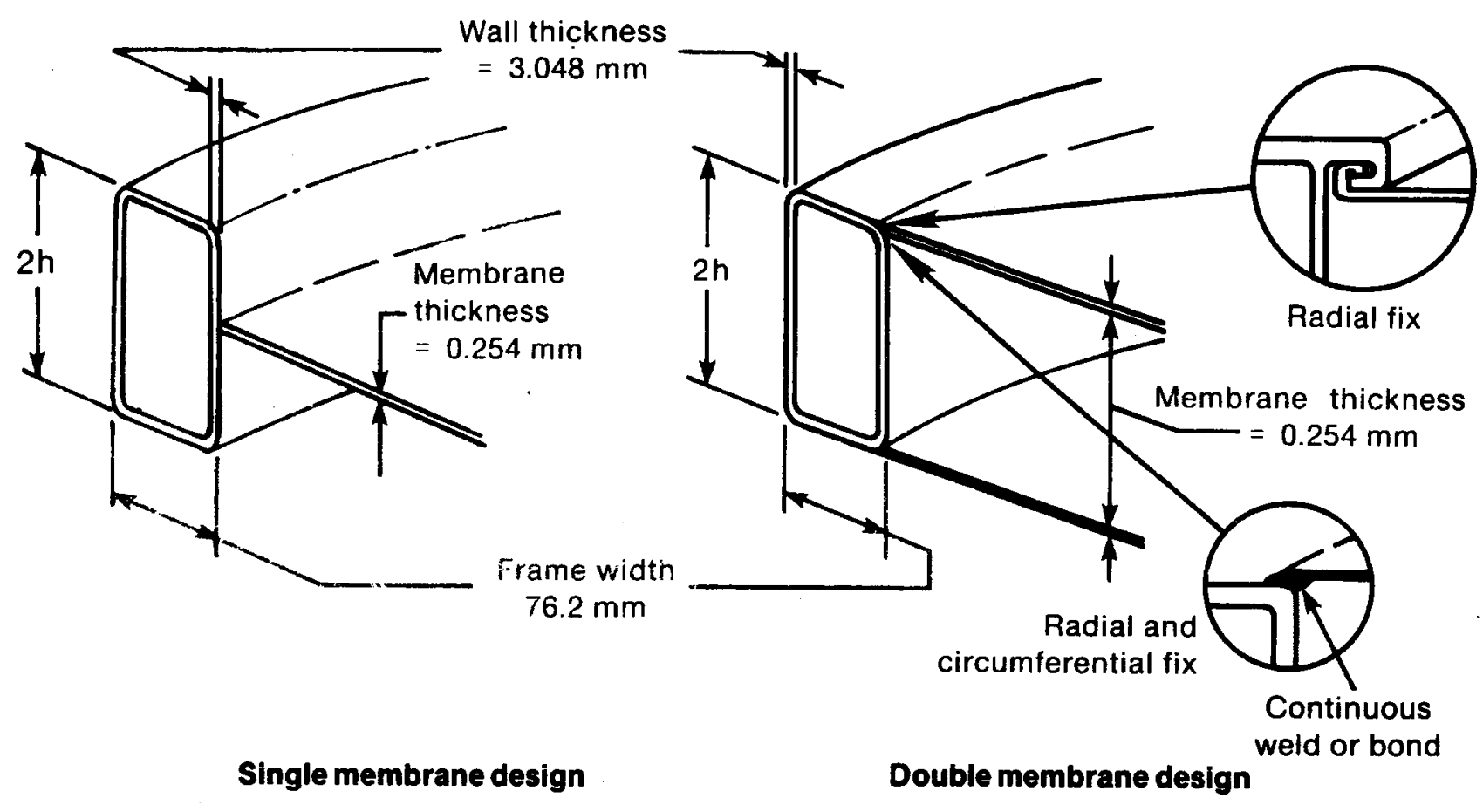

(a) Cross-section view for steel frame/membrane combination considered in analysis discussion

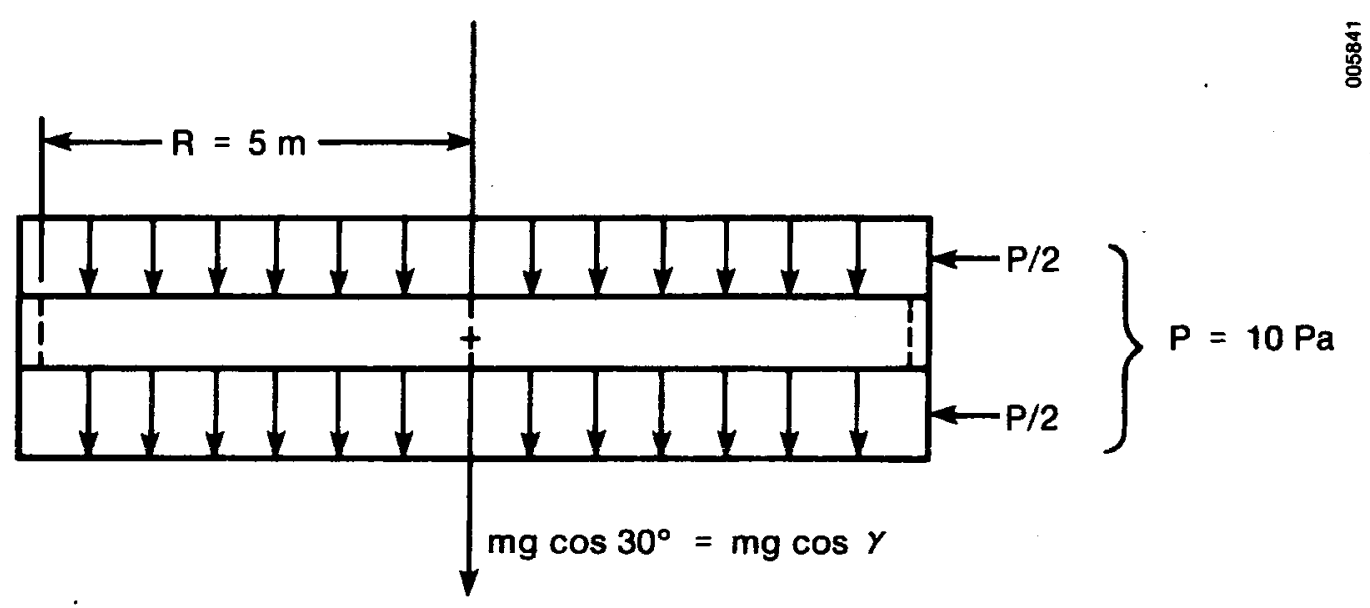

(b) Lateral view of assumed weight and pressure loading on module

Figure 5-1. Assumed Geometry and Loading on Modules Considered in Discussion of Results 


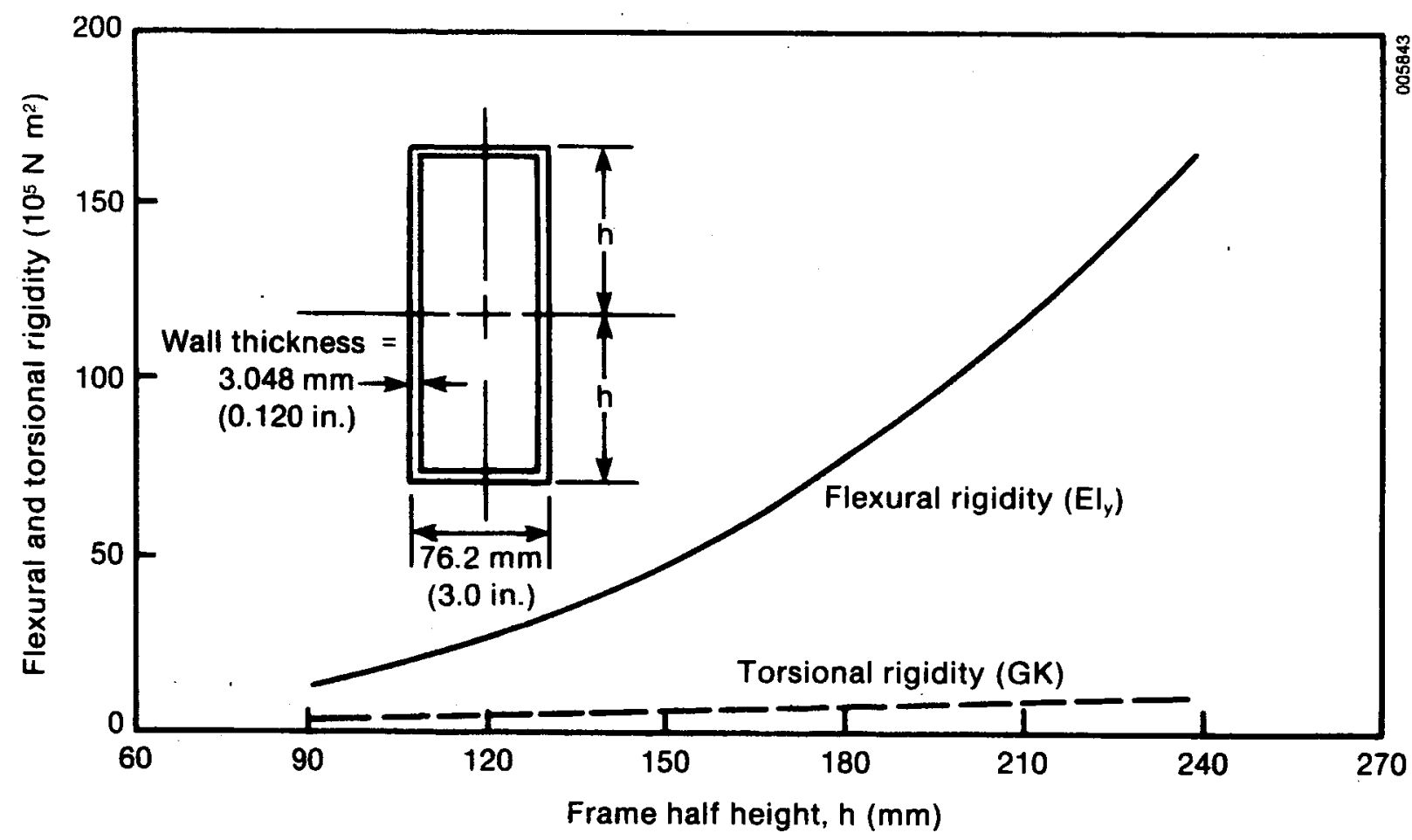

Figure 5-2. Plexural and Torsional Rigidity of Steel Frame Section as a Function of Frame Half Height

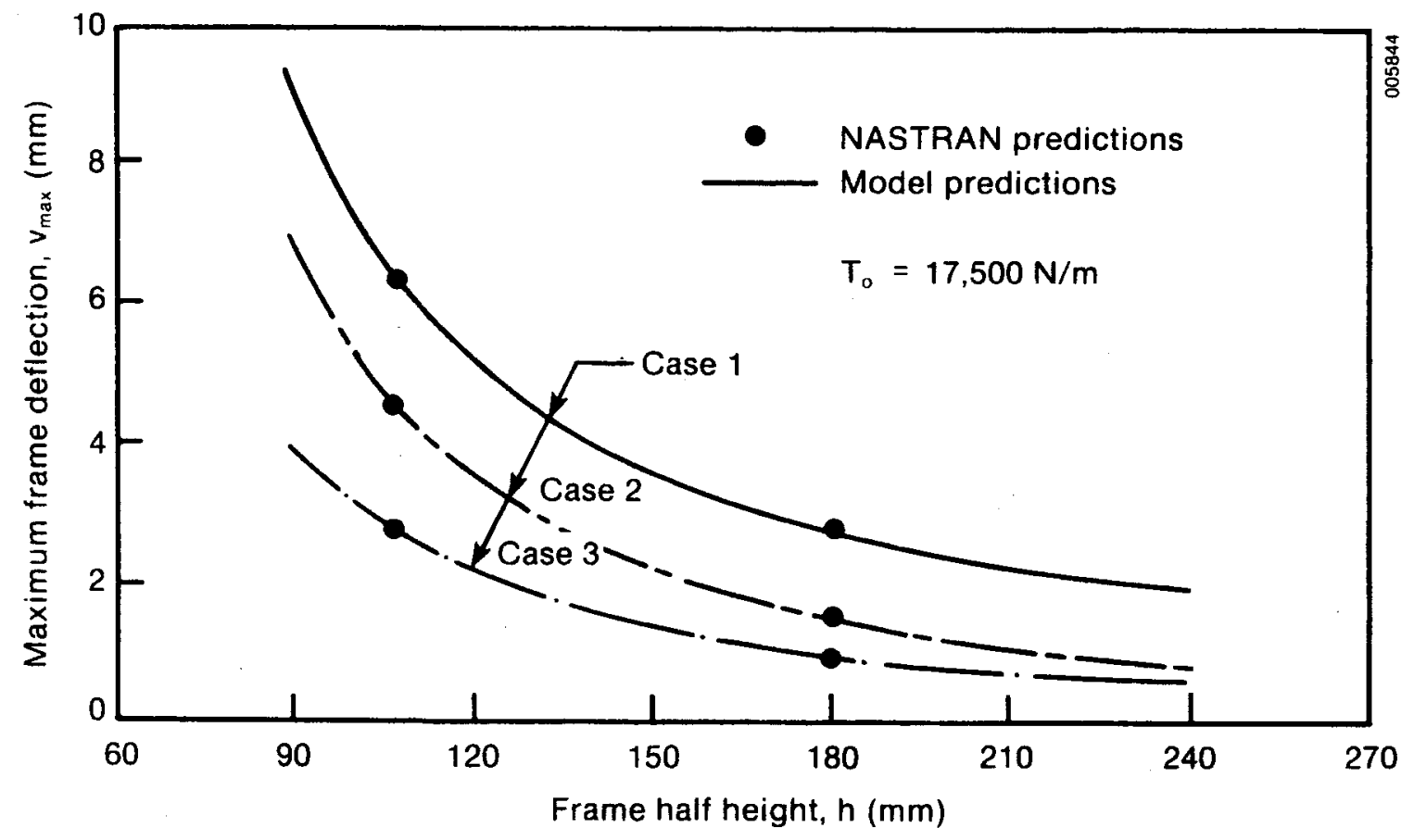

Figure 5-3. Maximun Frame Deflection as a Function of Frame Half Height for Design Cases 1,2 , and $3\left(T_{0}=17,500 \mathrm{~N} / \mathrm{m}\right)$ 
Figure 5-3 shows that both double-membrane designs are considerably stiffer to lateral loading than the single-membrane design. This is caused by two effects that couple the membrane stiffness with the problem in a manner not possible with the single-membrane concept. The curve corresponding to the highest overall stiffness and the lowest deflection, Case 3, represents a double-membrane concept where the attachment does not allow the membrane to move independently in either the radial or circumferential direction (i.e., a hard attachment) from that of the attachment point on the frame. Thus, the membrane not only inhibits the rolling of the frame, but the membrane also must strain the same amount as the frame at its attachment point. This strain compatibility effect is analogous to the membrane acting as an additional flange attached to the frame.

For Case 2 in which a radial-only constraint is assumed at the attachment, the membrane is allowed to move freely in the circumferentlal direction but not radially. In this case, the membranes exhibit only the roll or twist motion of the frame. However, this is a significant effect since frame twist and out-of-plane frame deflection are strongly coupled.

Figure 5-3 also shows that the relative benefit of double-membrane concepts increases with frame helght primarliy since the membrane offers more effective roll restraint as the membranes are spread farther apart and the effective moment arms are increased in length. Further, the benefit of "hard" versus "radial" attachment decreases as frame height increases because the bending resistance of the frame inireases relative to the membrane induced "flange" effect previously discussed. Thus, for the cases considered here the rollresistance effect is more dominant than the flange-induced effect.

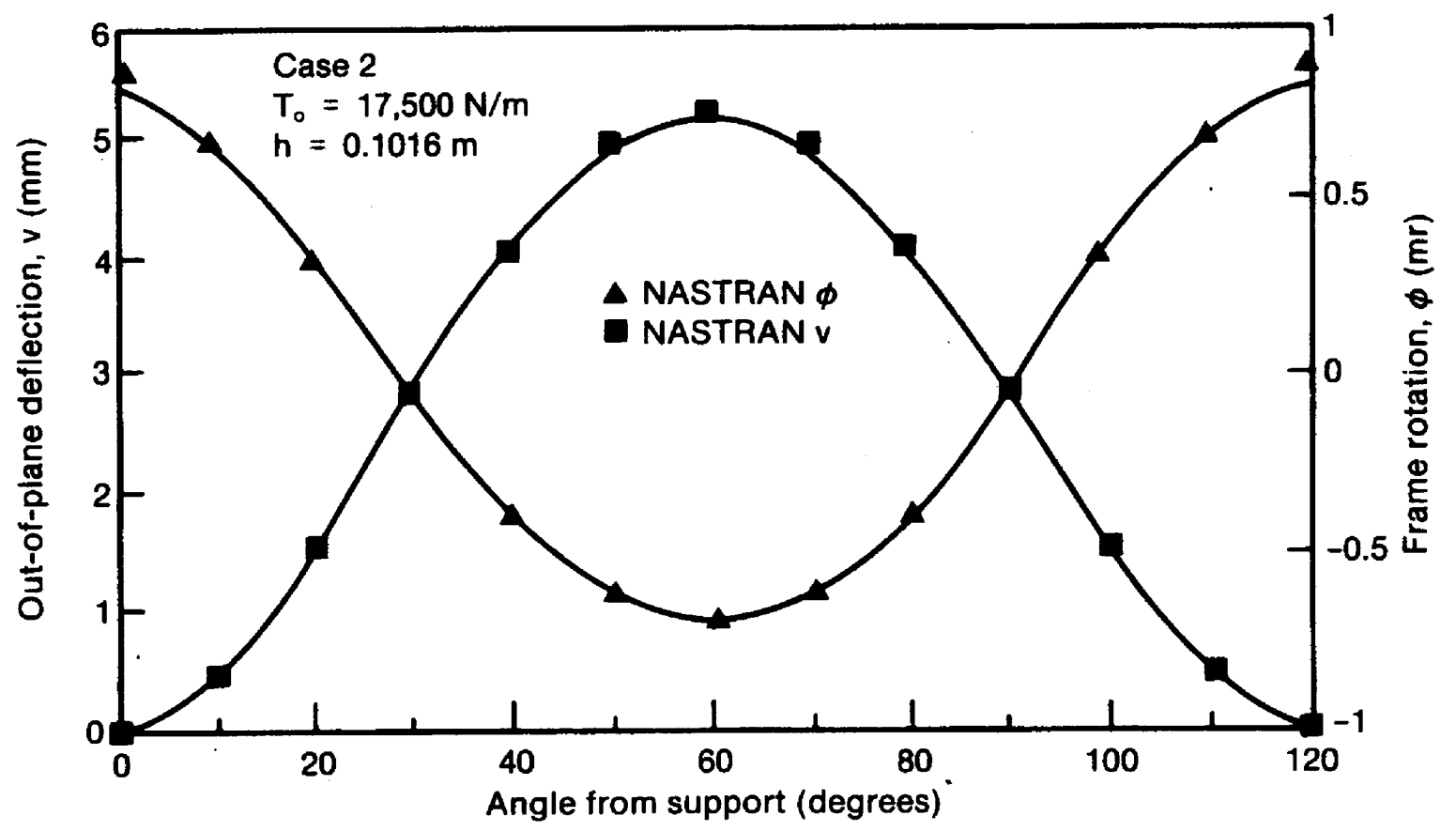

Figure 5-4. Frame Deflection and Twist as a Function of Angular Distance between the Support for Case $2\left(T_{0}=17,500 \mathrm{~N} / \mathrm{m}\right.$; $\mathbf{h}=0.1016 \mathrm{~m})$ 
Finally, also for comparison, both $v$ and $\phi$ are shown as a function of the circumferential coordinate $\theta$ for the Case 2 design in Figure 5-4 along with the NASTRAN predictions for a typical design. This particular figure corresponds to Case 3 (steel design) with a frame half height of $101.6 \mathrm{~mm}$, and a total membrane tension in the two membranes of $17,500 \mathrm{~N} / \mathrm{m}(100 \mathrm{lb} / \mathrm{in}$.$) .$ 


\section{SECTION 6.0}

\section{CONCLUSIONS}

The model described in this report, based on the comparisons with the more general NASTRAN computer code, appears to do a very good job of predicting the response of a stretched membrane module frame for the assumed geometric, lateral loading, and support conditions. For instance the model appears to faithfully predict the interaction of the membrane/frame combination for several assumed boundary conditions associated with either single or double stretched membrane module. As such the model should be of value in performing sizing and design trade-offs, and in developing understanding of the varlous stretched membrane response mechanisms and their interactions. To this end, a much more extensive analysis of varlous trade-offs is presented in a forthcoming report (Murphy, forthcoming).

The model does have limitations. As with any model, care should be exercised In its use, particularly to ensure that the inherent assumptions are consistent with the real problem being analyzed. Many of the assumptions, such as the requirements for uniform compressive force in the frame and the assumption of small strains with large displacement increments, appear to be quite adequate for the range of cases studied. However, the most sensitive and potentially problematic assumption appears to be the requirement that the in-plane membrane tension increments that result from the frame distortions be much smaller than the net initial pre-tension in the membrane. Without nearly uniform tension in the membrane the predicted surface deformation may be quite inaccurate. The exact value of tension increments relative to the initial tension, which results in unacceptable inaccuracies for the predicted surface deformations, is unknown, but it is clear that compressive loads in the membrane are not acceptable. Thus, the model can be used to indicate where a potential problem might exist but not to determine the full effect of the problem. The assumption of small tension increments will tend to be valid with higher initial pre-tensions, lower overall out-of-plane frame deformations, and possibly for cases where highly compliant membranes are coupled to a relatively stiff frame. However, the validity of the assumption may be required to result in good optical qualities since a nonuniform tension in the reflector membrane will result in additional and nonuniform deformations relative to the deformations experienced in a uniformly tensioned membrane.

The nearly constant membrane tension assumption also implicitly eliminates consideration of large axisymmetric diaphram deformation. Here again, if the pre-tension is reasonably high, then a very large axisymmetric deformation fleld, which would also imply unacceptable optical quality for hellostats, would probably be required (Murphy 1983).

We recommend that the consistency of the assumptions with the physical problem being studied always be compared with the predicted results where possible. For instance, if $i t$ is found that the calculated in-plane tension increments are comparable in magnitude to the stresses corresponding to the initial tension, then the predicted membrane surface deformations as noted above may have significant error even though the frame deformations may be quite accurately predicted. When it is not possible to verify the assumptions we recommend that additional care needs to be exercised in using the model. 
There are clearly several phenomena, though not belleved to be dominant, that may still be important and deserve further investigation. They include: nonuniform pressure loads, the effects of in-plane loads, the effects of initial imperfections including the superposition of initial model shapes with periods different from the frame support pattern, the effect of radial frame deformation increments (the initial radial deformations associated with the pretensioning are implicitly accounted for), and potential effects caused by different frame support conditions that may introduce local radial hard points and bending moments at the supports. Many of these effects can be accounted for by adding appropriate modifications to the current model. 


\section{SECTION 7.0}

\section{REFERENCES}

Meek, H. R., Feb. 1969, "Three-Dimensional Deformation and Buckling of a Circular Ring of Arbitrary Section," Transactions of the ASME, Journal of Engiueering for Industry, pp. 226-272.

Murphy, L. M., forthcoming, Structural Design Considerations for StretchedMembrane Hellostat Reflector Modules with Stability and Initial Imperfection Considerations, SERI/TR-253-2338, Golden, CO: Solar Energy Research Institute.

Murphy, L. M., May 1983, Technical and Cost Benefits of Lightweight, Stretched-Membrane Heliostats, SERI/TR-253-1818, Golden, CO: Solar Energy Research Institute.

Murphy, L. M., and D. V. Sallis, May 1984, Analytical Modeling and Structural Response of a Stretched-Membrane Reflectlve Module, SERI/TR-253-2101, Golden, CO: Solar Energy Research Institute.

Schaeffer, H. G., 1979, MSC/NASTRAN PRIMER - Static and Normal Mode1 Analys 1s: A Study of Computerized Technology, Mount Vernon, NH: Schaeffer Analysis, Inc.

Thompson, J. M. T., and G. W. Hunt, 1984, Elastic Instablilty Phenomena, NY: John Wiley and Sons.

Timoshenko, S. P., and J. P. Gere, 1961, Theory of Elastic Stability, NY: McGraw Hill Book Co.

Washizu, K., 1982, Variational Methods in Elasticity and Plasticity, NY: Pergamon Press, pp. 138-150. 


\section{APPENDIX A \\ IN-PLANE MEGBRANE RRSPONSE}

The description for the in-plane membrane response follows from the plane stress/strain analysis of Sokolnikoff* where complex potentials are used. In this approach the linear equilibrium equations are transformed into a simple boundary value problem where either the tractions or displacements are defined on the boundary. The resulting boundary value problem is described in terms of two analytic functions of a complex variable $Z$. The solution to the boundary value problem is obtained by describing both the analytical functions and the prescribed displacement or loading condition on the boundary with a complex Fourier series and then by determining the coefficients to the series for the analytical functions by satisfying the boundary conditions. Sokolntkoff provides a description of the needed displacements and stresses in terms of the analytic functions $\Phi(Z)$ and $\Psi(Z)$ within the region as well as the appropriate coefficlent constraint conditions for a circular region, and for either prescribed displacements or loads on the boundary. The details of this analysis will not be reproduced here, but the princlpal results for two cases will be given. The two cases correspond to elther harmonic displacements or harmonic stresses prescribed on the boundary of the circular region. This approach is motivated by the assumed displacement function for the frame and the compatibility conditions, Eqs. 3-11, 3-12, 4-4, and 4-5.

Sokolnikoff (pp. 281-282) gives the following relationships, corresponding to a circular region of radius a :

$$
\begin{gathered}
2 G_{m}\left(u_{r}+i u_{\theta}\right)=e^{-1 \theta}\left[\Gamma \Phi(z)-z \bar{\Phi}^{\prime}(z)-\Phi(z)\right] \\
\tau_{r r}+\tau_{\theta \theta}=4 \operatorname{Re}\left[\Phi^{\prime}(z)\right] \\
\tau_{\theta \theta}-\tau_{r r}+21 \tau_{r \theta}=2\left[\bar{z} \Phi^{\prime \prime}(z)+\Psi^{\prime}(z)\right] e^{21 \theta},
\end{gathered}
$$

where $u_{r}$ and $u_{\theta}$ are the displacments in the radial and circumferential directions, respectively, and where $\tau_{r r}, \tau_{\theta \theta}$, and $\tau_{r \theta}$ are the normal and shear stress components corresponding to cylindrical coordinates. The term $G_{m}$ is the membrane shear modulus and $\Gamma$ is a material constant defined in terms of the Poisson ratio $\nu_{m}$ for the membrane by

$$
\Gamma=\frac{3-4 v_{m} \text { for plane strain }}{\frac{3-v_{m}}{1+v_{m}}} \text { for plane stress. }
$$

The plane stress case is of interest in this current analysis.

*Sokolnikoff, I. S., Mathematical Theory of Elasticity, 2nd Edition, New York: McGraw-H111, 1956. 
Also in Eq. A-2 Re denotes the real part of the quantity following it, the prime denotes differentation with respect to $Z$, and the bar over the quantity In Eq. A-1 [e.g., $\left.\bar{\Phi}^{\prime}(\mathrm{z})\right]$ denotes the "conjugate of" as defined in complex analysis.

The terms $\phi(Z)$ and $\Psi(Z)$ are defined by

and

$$
\Phi(z)=\sum_{k=1}^{\infty} c_{k}\left(\frac{z}{a}\right)^{k}
$$

$$
\Psi(z)=\sum_{k=0}^{\infty} d_{k}\left(\frac{z}{a}\right)^{k}
$$

where $c_{k}$ and $d_{k}$ are complex constants determined from the boundary conditions. In the case of prescribed stresses $\left(T_{1}, T_{2}\right)$ on the boundary, the appropriate boundary condition is written as*

$$
f_{1}(\theta)+1 f_{2}(\theta)=i a \int\left(T_{1}+1 T_{2}\right) d \theta=\sum_{k=-\infty}^{\infty} A_{k} e^{i k \theta} .
$$

Then combining Eqs. $A-5, A-3$, and $A-6$ results in

$$
\begin{gathered}
c_{1}+\bar{c}_{1}=A_{1} \\
c_{k}=A_{k} ; \text { for } k \geqslant 2 \\
d_{k}=\bar{A}_{k}-(k+2) A_{k+2} ; \text { for } k=0,1,2, \ldots
\end{gathered}
$$

In the case of prescribed Cartesian components $g_{1}(\theta)$ and $g_{2}(\theta)$ of the radial and circumferential displacements on the boundary, the boundary condition is written

$$
2 G_{m}\left(g_{1}(\theta)+1 g_{2}(\theta)\right)=\sum_{k=-\infty}^{\infty} B_{k} e^{i k \theta}
$$

Then combining Eqs. $A-1, A-5$, and $A-8$ results in

$$
\begin{gathered}
\Gamma c_{1}-\bar{c}_{1}=B_{1} \\
\Gamma c_{k}=B_{k} ; \text { for } k>1
\end{gathered}
$$

*The subscripts 1 and 2 correspond to the respective rectangular components in the complex plane. 


$$
\bar{d}_{k}=-B_{-k}-(k+2) \bar{c}_{k+2} ; \text { for } k>0 \text {. }
$$

Using the above approach and definftions, the results for prescribed harmonic boundary surface loads or displacements can be calculated in a straightforward, albeit somewhat tedious, manner and are given in Table A-1.

The results provided in Table A-1 can now be used to define the response of the membrane under different attachment boundary conditions in terms of the frame displacement coefficients $a_{k}$ and $b_{k}$. Hence, using the harmonic representation for the stresses and displacements, $U_{5}$ (Eq. 3-10) can be evaluated for the specific boundary conditions of interest. First consider the case of a totally fixed attachment where the displacements of the membrane (both radial and circumferential) must match the displacements of the frame at the attachment. For this case we determine the contribution to $U_{5}$ from a single harmonic displacement set, $u_{r k}$ and $u_{\theta k}$. Then from Eqs. 3-11, 3-12, 4-4, and 4-5:

$$
u_{r k}=h \phi_{k}=h b_{k} \cos \frac{2 \pi k}{p}
$$

and

$$
u_{\theta k}=\frac{-a h}{R^{2}}\left(v_{k}\right)=\frac{-a h a_{k}}{R^{2}}\left(\frac{2 \pi k}{p}\right) \sin \frac{2 \pi k}{p}
$$

For a given $u_{r k}$ displacement the stresses from Table A-l could be of the form

$$
\tau_{r r_{k}}=h b_{k} K_{11}(k) \cos \frac{2 \pi k}{p} \theta
$$

and

$$
\tau_{r \theta_{k}}=h b_{k} K_{12}(k) \sin \frac{2 \pi k}{p} \theta
$$

where from Table A-1 with $n=\frac{2 \pi k}{p}$

$$
\mathrm{k}_{11}(\mathrm{k})=\frac{\mathrm{G}_{\mathrm{m}}}{\mathrm{a}}\left[\frac{\mathrm{n}+1}{\Gamma}+(\mathrm{n}-1)\right]=\frac{\mathrm{G}_{\mathrm{m}}}{\mathrm{a} \Gamma}\left[\frac{2 \pi \mathrm{k}}{\mathrm{p}}(1+\Gamma)+(1-\Gamma)\right]
$$

and

$$
\mathrm{K}_{12}(\mathrm{k})=\frac{\mathrm{G}_{\mathrm{m}}}{\mathrm{a}}\left[\frac{\mathrm{n}+\mathrm{i}}{\Gamma}-(\mathrm{n}-1)\right]=\frac{\mathrm{G}_{\mathrm{m}}}{\mathrm{a} \Gamma}\left[\frac{2 \pi \mathrm{k}}{\mathrm{p}}(1-\Gamma)+(1+\Gamma)\right] .
$$

Physically, $K_{11}(k)$ and $K_{12}(k)$ represent the in-plane stiffness, per unit cross-sectional area, for the membrane and correspond to the modal displacement of period $k$.

Likewise, for a given $u_{\theta k}$ displacement, the corresponding stress increments are

$$
\begin{aligned}
& \tau_{r_{\theta_{k}}}=\frac{-a h}{R^{2}}\left(\frac{2 \pi k}{p}\right) a_{k} K_{11}(k) \sin \frac{2 \pi k}{p} \theta \\
& \tau_{r r_{k}}=\frac{-a h}{R^{2}}\left(\frac{2 \pi k}{p}\right) a_{k} K_{12}(k) \cos \frac{2 \pi k}{p} .
\end{aligned}
$$


Table A-1. In-Plane Membrane Response Results

\begin{tabular}{|c|c|c|c|c|}
\hline $\begin{array}{c}\text { Case } \\
\text { Quantity }\end{array}$ & $\begin{array}{c}\text { Applied Normal } \\
\text { Radial Load at } r=a \\
n>2\end{array}$ & $\begin{array}{l}\text { Applied Shear } \\
\text { at } r=a \\
n>2\end{array}$ & $\begin{array}{c}\text { Applled Radial } \\
\text { Displacement at } \\
r=a \\
n>2\end{array}$ & $\begin{array}{c}\text { Applied Circumferential } \\
\text { D1splacement at } \\
r=a \\
n>2\end{array}$ \\
\hline $\begin{array}{l}\text { Boundary } \\
\text { Conditions }\end{array}$ & $\begin{array}{l}T_{1}=\Delta T_{0} \cos n \theta \cos \theta \\
T_{2}=\Delta T_{0} \cos n \theta \sin \theta\end{array}$ & $\begin{array}{l}T_{1}=-\Delta S_{0} \sin n \theta \sin \theta \\
T_{2}=\Delta S_{0} \sin n \theta \cos \theta\end{array}$ & $\begin{array}{l}g_{1}=u_{a 0} \cos n \theta \cos \theta \\
g_{2}=u_{a o} \cos n \theta \sin \theta\end{array}$ & $\begin{array}{l}g_{1}=-u_{\theta_{0}} \sin n \theta \sin \theta \\
g_{2}=u_{\theta_{0}} \sin n \theta \cos \theta\end{array}$ \\
\hline$\Phi$ & $\frac{\Delta T_{0} a}{2}\left(\frac{1}{n+1}\right)\left(\frac{L}{a}\right)^{n+1} e^{1(n+1) \theta}$ & $\frac{\Delta S_{0} a}{2}\left(\frac{1}{n+1}\right)\left(\frac{r}{a}\right)^{n+1} e^{1(n+1) \theta}$ & $\frac{G_{m_{a 0}}}{\Gamma}\left(\frac{r}{a}\right)^{n+1} e^{1(n+1) \theta}$ & $\frac{G_{m}{ }^{u} \theta 0}{\Gamma}\left(\frac{r}{a}\right)^{n+1} e^{1(n+1) \theta}$ \\
\hline$\Psi$ & $\frac{-\Delta T_{0} a}{2}\left(\frac{n}{n-1}\right)\left(\frac{r}{a}\right)^{n-1} e^{1(n-1) \theta}$ & $\frac{\Delta S_{0} a}{2}\left(\frac{2-n}{n-1}\right)\left(\frac{r}{a}\right)^{n-1} e^{1(n-1) \theta}$ & $-G_{m} u_{a o}\left[1+\left(\frac{n+1}{\Gamma}\right)\right]\left(\frac{r}{a}\right)^{n-1} e^{1(n-1) \theta}$ & $G_{m}{ }^{u} \theta_{0}\left[1-\left(\frac{n+1}{\Gamma}\right)\right]\left(\frac{r}{a}\right)^{n-1} e^{1(n-1) \theta}$ \\
\hline$\tau_{r r(a, \theta)}$ & $\Delta T_{0} \cos n \theta$ & 0 & $\frac{G_{m} u_{a o}}{a}\left[\frac{n+1}{\Gamma}+(n-1)\right] \cos n \theta$ & $\frac{{ }_{m}{ }^{u} \theta 0}{a}\left[\frac{n+1}{\Gamma}-(n-1)\right] \cos n \theta$ \\
\hline$\tau_{r \theta(a, \theta)}$ & 0 & $\Delta S_{0} \sin n \theta$ & $\frac{G_{m^{u}} a_{0}}{a}\left[\frac{n+1}{\Gamma}-(n-1)\right] \sin n \theta$ & $\frac{G_{m}{ }^{u} \theta 0}{a}\left[\frac{n+1}{\Gamma}+(n-1)\right] \sin n \theta$ \\
\hline$u_{r}(a, \theta)$ & $\frac{\Delta T_{0} a_{1}}{4 G_{m}}\left[\frac{\Gamma(n-1)+\langle n+1\rangle}{(n+1)(n-1)}\right] \cos n \theta$ & $\frac{\Delta S_{0} a}{4 G_{m}}\left[\frac{\Gamma(n-1)-(n+1)}{(n+1)(n-1)}\right] \cos n \theta$ & $u_{a o} \cos n \theta$ & 0 \\
\hline$u_{\theta(a, \theta)}$ & $\frac{\Delta T_{0} a^{a}}{4 G_{m}}\left[\frac{\Gamma(n-1)-(n+1)}{(n+1)(n-1)}\right] \sin n \theta$ & $\frac{\Delta S_{0} a^{a}}{4 G_{m}}\left[\frac{\Gamma(n-1)+(n+1)}{(n+1)(n-1)}\right] \sin n \theta$ & 0 & $\mathrm{u}_{\theta_{0}} \sin \mathrm{n} \theta$ \\
\hline
\end{tabular}


Thus, the contribution to $U_{5}$ from the $k$ th deformation mode caused by the membrane is

$\mathrm{U}_{5 \mathrm{k}}=\frac{\mathrm{at}}{2} \int_{\mathrm{m}}^{\mathrm{p}}\left[\mathrm{hb}_{\mathrm{k}} \mathrm{K}_{11}(\mathrm{k}) \cos \frac{2 \pi \mathrm{k}}{\mathrm{p}} \theta-\frac{\mathrm{aha} \mathrm{a}_{\mathrm{k}}}{\mathrm{R}^{2}}\left(\frac{2 \pi \mathrm{k}}{\mathrm{p}}\right) \mathrm{K}_{12}(\mathrm{k}) \cos \frac{2 \pi \mathrm{k}_{\theta}}{\mathrm{p}}\right] \mathrm{hb}_{\mathrm{k}} \cos \frac{2 \pi \mathrm{k}_{\theta}}{\mathrm{p}} \mathrm{d \theta}$

$+\frac{a t_{m}}{2} \int_{0}^{p}\left\{\left[-\frac{-a h a_{k}}{R^{2}}\left(\frac{2 \pi k}{p}\right) k_{11}(k) \sin \frac{2 \pi k_{0}}{p}+h b_{k} k_{12}(k) \sin \frac{2 \pi k}{p} \theta\right]\right.$ $\left.\left(\frac{-\mathrm{aha}}{\mathrm{R}^{2}}\right) \frac{2 \pi \mathrm{k}}{\mathrm{p}} \sin \frac{2 \pi \mathrm{k}_{\mathrm{g}}}{\mathrm{p}}\right\} \mathrm{d} \theta$.

Equation A-18 is easily integrated using the orthogonality conditions and results in

$$
\begin{aligned}
\mathrm{U}_{5 \mathrm{k}} & =\frac{\mathrm{at} \mathrm{m}_{\mathrm{m}}}{2} \eta_{\mathrm{k}} \mathrm{p}\left\{\mathrm{K}_{11}(\mathrm{k})\left[\mathrm{h}^{2} \mathrm{~b}_{\mathrm{k}}^{2}+\left(\frac{\mathrm{ah}}{\mathrm{R}^{2}} \cdot \frac{2 \pi \mathrm{k}}{\mathrm{p}}\right)^{2} \mathrm{a}_{\mathrm{k}}^{2}\right]\right. \\
& \left.-2 \delta \mathrm{K}_{12}(\mathrm{k})\left(\mathrm{h} \mathrm{b}_{\mathrm{k}}\right)\left(\frac{\mathrm{aha} \mathrm{k}}{\mathrm{r}^{2}}\right)\left(\frac{2 \pi \mathrm{k}}{\mathrm{p}}\right)\right\}
\end{aligned}
$$

where

and

$$
\eta_{k}=\left\{\begin{array}{l}
1 \text { for } k=0 \\
1 / 2 \text { for } k=1,2 \ldots . m
\end{array}\right.
$$

$$
\delta=\left\{\begin{array}{l}
0 \text { for } k=0 \\
1 \text { for } k=1,2 \ldots . m .
\end{array}\right.
$$

Next consider the case of a simple radial constraint. where the membrane is free to slide in the circumferential direction with no resistance but is constralned to follow the frame in the radial direction. In this case only a radial surface traction is applied with zero shear $\left(e_{. g}, \tau_{r}=0\right)$ traction at the boundary. Further, no restrictions are placed on the circumferential displacements by this boundary condition. Then, using the applied traction boundary condition and an evaluation process similar to that leading to Eqs. $A-11$ through $A-17$, the following relations result:

$$
\tau_{r r_{k}}=h b_{k} K_{22}(k) \cos \frac{2 \pi k}{p} \theta
$$

and

$$
\tau_{\mathrm{r} \theta}=0,
$$

where

$$
\mathrm{K}_{22}(\mathrm{k})=4 \frac{\mathrm{G}_{\mathrm{m}}}{\mathrm{a}}\left[\frac{\mathrm{n}^{2}-1}{\Gamma(\mathrm{n}-1)+(\mathrm{n}+1)}\right]=4 \frac{\mathrm{G}_{\mathrm{m}}}{\mathrm{a}}\left[\frac{\left(\left(\frac{2 \pi \mathrm{k}}{\mathrm{p}}\right)^{2}-1\right)}{\frac{2 \pi \mathrm{k}}{\mathrm{p}}(\Gamma+1)+(1-\Gamma)}\right] \cdot \quad(\mathrm{A}-24)
$$


Thus, following the procedure above, the contribution of the $k$ th mode to $U_{5}$ is given by

$$
\mathrm{U}_{5 \mathrm{k}}=\frac{\mathrm{at}}{2} \eta_{\mathrm{k}} \mathrm{p} \mathrm{K}_{22}(\mathrm{k}) \mathrm{h}^{2} \mathrm{~b}_{\mathrm{k}}^{2} \text {, }
$$

where $\eta_{k}$ is defined as in Eq. A-19.

One final point should be noted: Eqs. $A-14$ and $A-24$ are valid for cases where $2 \pi k / p>2$. Thus, they are generally not valid for $k=0$ or $k=1$; no further problems will exist for three or more supports. The $k=1$ term is not of interest since equilibrium will not be satisfled. Further, the $k=0$ term is not applicable for the $u_{\theta}$ displacement. $A k=0$ term, however, can arise with the $u_{r}$ displacement (1.e., corresponding to uniform frame rotation). The appropriate coefficient corresponding to $b_{0}$ is easily found to be

$$
\mathrm{K}_{11}(0)=\mathrm{K}_{22}(0)=\frac{4 \mathrm{G}_{\mathrm{m}}}{\mathrm{a}(\Gamma-1)} \text {. }
$$




\section{APPENDIX B \\ APPROXIMATE OUT-OF-PLANE HIMBRANE RESPONSE}

Murphy and Sallis* showed that for a linear membrane response, corresponding to a constant tension in the membrane, the deformation $w$ can be expressed as the sum of two contributions; one corresponding to axisymmetric deformation $\mathrm{w}_{1}$ caused by the uniform pressure loading and the other corresponding to the nonzero boundary conditions arising from the frame (boundary) distortion $w_{2}$. The resulting load displacement relations in terms of the uniform pressure $P$ and the frame displacements $v$ and $\phi$ are given for a single membrane by

$$
\begin{aligned}
w(r, \theta) & =\frac{P a^{2}}{4 T_{0}}\left[1-\left(\frac{r}{a}\right)^{2}\right]+\frac{1}{p} \int_{0}^{p}[v(\xi)+\ell \phi(\xi)] d \xi \\
& +\frac{2}{p} \sum_{k=1}^{\infty}\left(\frac{r}{a}\right)^{\frac{2 \pi k}{p}} \cos \frac{2 \pi k \theta}{p} \int_{0}^{p}[v(\xi)+\ell \phi(\xi)] \cos \frac{2 \pi k \xi}{p} d \xi,
\end{aligned}
$$

where $\mathrm{p}$ is the symmetry period corresponding to the placement of the supports. Now if the expressions for $v$ and $\phi$ (Eqs. 4-1 and 4-2) are substituted into Eq. B-1, then w can be written as

$w(r, \theta)=\frac{P a^{2}}{4 T_{0}}\left[1-\left(\frac{r}{a}\right)^{2}\right]+\ell b_{0}+\sum_{k=1}^{m} a_{k}-\sum_{k=1}^{m}\left(a_{k}-\ell b_{k}\right)\left(\frac{r}{a}\right)^{\frac{2 \pi k}{p}} \cos \frac{2 \pi k \theta}{p}$.

Thus, in terms of the arbitrary coefficients $a_{k}$ and $b_{k}(k=1,2 \ldots . . m)$ [to be determined from the variational process] $w(r, \theta)$ can be writ,teh as

$$
\begin{aligned}
w(r, \theta)= & a_{0}\left[1-\left(\frac{r}{a}\right)^{2}\right]+\sum_{k=1}^{m} a_{k}^{\prime}\left[1-\left(\frac{r}{a}\right)^{\frac{2 \pi k}{p}} \cos \frac{2 \pi k \theta}{p}\right] \\
& +\ell \sum_{k=0}^{m} b_{k}\left(\frac{r}{a}\right)^{\frac{2 \pi k}{p}} \cos \frac{2 \pi k \theta}{p},
\end{aligned}
$$

where the first term corresponds to $w_{1}$, the axisymmetric membrane deformation, and the last two summations correspond to the asymmetric membrane deformation $w_{2}$, as described in Murphy and Sallis. Further, with Eq. B-3 the corresponding expressions for $w_{r}$ and $l / r w_{\theta}$ are easily determined.

*Murphy, L. M., and D. V. Sallis, Analyt1cal Modeling and Structural Response of a Stretched-Membrane Reflective Module, SERITTR-253-2101, Golden, CO: Solar Energy Research Institute, May 1984. 


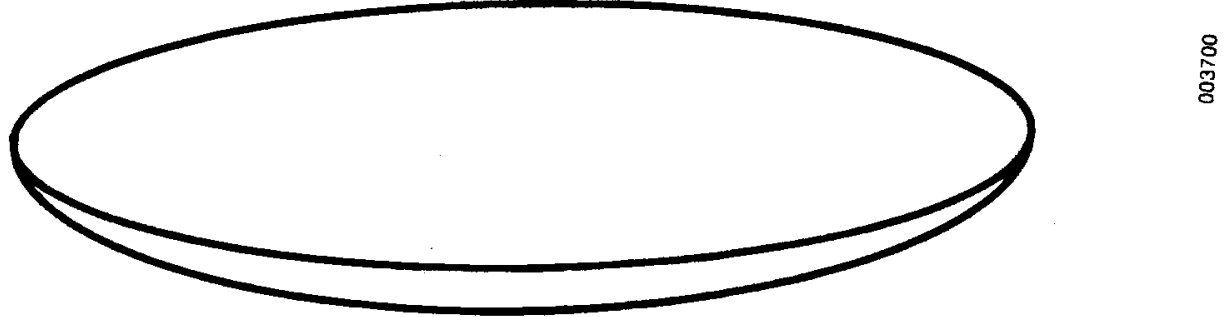

a) $w_{1}$ axisymmetric portion of membrane deformation

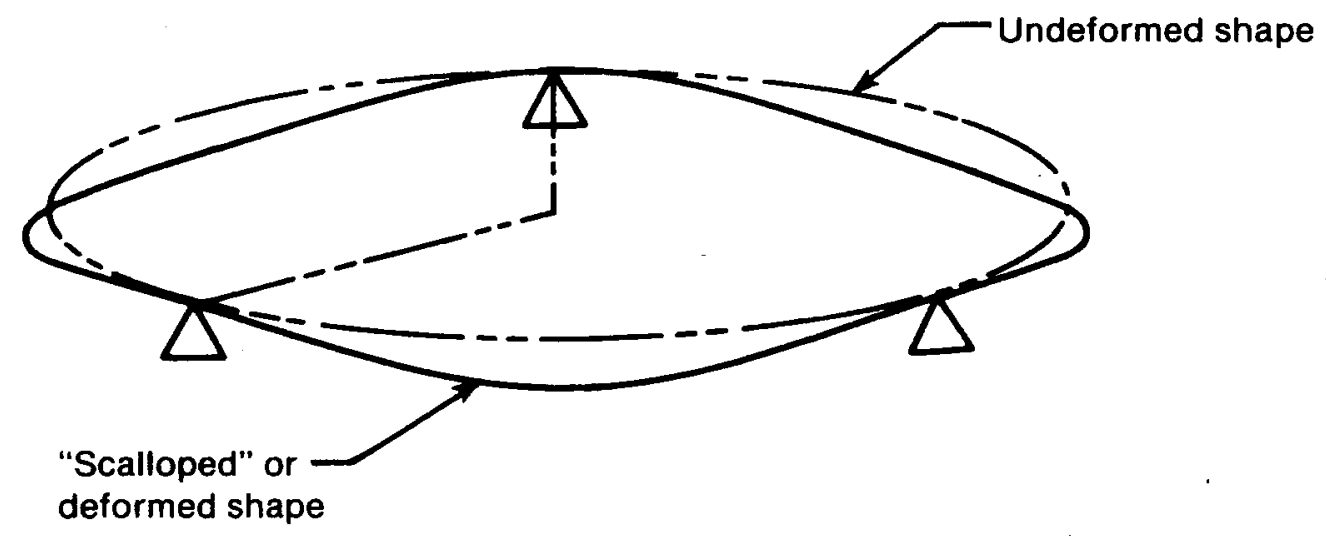

b) $w_{2}$ nonsymmetric, "scalloped," membrane shape caused by support constraints

Figure B-1. Axisymetric and Nonsymmetric Deformation Patterns Caused by Iateral Loading and Support Constraints 


\section{APPENDIX C \\ EVALUATION OF THE STIFFNESS MATRIX AND LOAD VECTORS}

The potential energy was expressed in Eqs. 4-8 through 4-12 in the body of this report by

$$
\begin{aligned}
& v_{e}=\frac{1}{2} \lambda^{T} \bar{U} \lambda-\lambda^{T} \bar{w} \\
& \frac{1}{2} \lambda^{T} \bar{U} \lambda=\sum_{j=1}^{6} U_{j}
\end{aligned}
$$

and

where

$$
\lambda^{T} \bar{W}=\sum_{j=1}^{3} W_{j}
$$

and

$$
\overline{\mathrm{U}}=\sum_{j=1}^{6} \overline{\mathrm{U}}_{j}
$$

$$
\bar{w}=\sum_{j=1}^{3} \bar{w}_{j},
$$

where $\lambda$ is the coefficlent vector as defined in Eq. 4-7. The contributions to $\bar{U}$ from $U_{j}(j=1, \ldots . .6)$ and to $\bar{W}$ from $W_{j}(j=1, \ldots . .3)$ are determined by using the coordinate functions as defined in Eqs. 4-4 and 4-5. Consider first as an example the term $U$ from Eq. 3-4:

$$
U_{1}=\frac{E I_{y}}{2 R} \int\left(\frac{v^{\prime \prime}}{R}-\phi\right)^{2} d \theta,
$$

then $\mathbf{v}$ and $\phi$ can be written

$$
v=\lambda^{T} \bar{v}
$$

and

$$
\phi=\lambda^{\mathrm{T}} \bar{\phi},
$$

where

$$
\overrightarrow{\mathrm{v}}^{\mathrm{T}}=\left[0, \mathrm{v}_{1}, \mathrm{v}_{2}, \ldots . \mathrm{v}_{\mathrm{m}}, 0, \ldots . . .0\right]
$$

and

$$
\bar{\phi}^{\mathrm{T}}=\left[0, \ldots . . . \cdot 0, \phi_{1} \ldots . . . \phi_{\mathrm{m}}\right] .
$$

The derivatives of $v$ also follow from Eqs. $C-1$ and $c-3$ and can be written as

$$
v^{\prime \prime}=\lambda^{T} \bar{v}^{\prime \prime},
$$


where

$$
\overline{\mathrm{v}}^{\prime \prime}=\left[0, \mathrm{v}_{1}^{\prime \prime}, \mathrm{v}_{2}^{\prime \prime} \ldots . . \mathrm{v}_{\mathrm{m}}^{\prime \prime}, 0,0, \ldots .0\right] .
$$

Then, using the above definitions, $U_{1}$ can be written as

$$
\mathrm{U}_{1}=\frac{1}{2} \lambda\left[\frac{\mathrm{EI} \mathrm{y}}{\mathrm{R}} \int_{0}^{\mathrm{p}}\left(\frac{\overline{\mathrm{v}}^{\prime \prime}}{\mathrm{R}}-\bar{\phi}\right)\left(\frac{\overline{\mathrm{v}}^{\prime}}{\mathrm{R}}-\bar{\phi}\right)^{\mathrm{T}} \mathrm{d} \theta\right] \lambda .
$$

Thus, comparing Eqs. 4-9 and 4-11 we can see that $\overline{\mathrm{U}}_{1}$ is given by

$$
\overline{\mathrm{U}}_{1}=\frac{E I_{\mathrm{y}}}{\mathrm{R}} \int_{0}^{\mathrm{p}}\left(\frac{\overline{\mathrm{v}}^{\prime \prime}}{\mathrm{R}}-\bar{\phi}\right)\left(\frac{\overline{\mathrm{v}}^{\prime} \cdot}{\mathrm{I}}-\bar{\phi}^{\mathrm{T}}\right) \mathrm{d} \theta,
$$

where the integration. Is carried out over one symmetry period of the membrane/frame combination. Note that the quantity in Eq. C-8 is a $(2 m+2 \times 2 m+2)$ matrix.

$\mathrm{U}_{2}$ through $\mathrm{U}_{4}$ ean be written in an exactly analogous manner along with their corresponding contributions to $\bar{U}$.

The contribution to $\bar{U}$ from $U_{5}$ (i.e., $\bar{U}_{5}$ ) follows directly from elther Eq. A-19 or $A-25$ along with Eqs. A-14, A-15, A-24, and A-26, depending on the boundary condition selected. The contribution to $\bar{U}$ from $U_{6}$ follows from $E q .3-13$ and the definition of $w, E q . B-3$. Thus,

$$
\begin{aligned}
& \mathrm{U}_{6}=\frac{\mathrm{T}_{\mathrm{o}}}{2} \iint\left[\mathrm{w},{ }^{2} \mathrm{r}+\left(\frac{1}{\mathrm{r}} \mathrm{w}, \theta\right)^{2}\right] \mathrm{r} d \mathrm{r} d \theta \\
& =\frac{1}{2} \lambda^{T}\left\{T_{O} \int_{0}^{p} \int_{0}^{a}\left[\bar{w}, r, \bar{w}, \frac{T}{r}+\frac{1}{r} \bar{w}, \theta \frac{1}{r} \bar{w}, \frac{T}{\theta}\right] r d r d \theta\right\} \lambda,
\end{aligned}
$$

where from Eqs. B-3 and 4-7 we get

$$
w=\lambda^{T} \bar{w},
$$


where

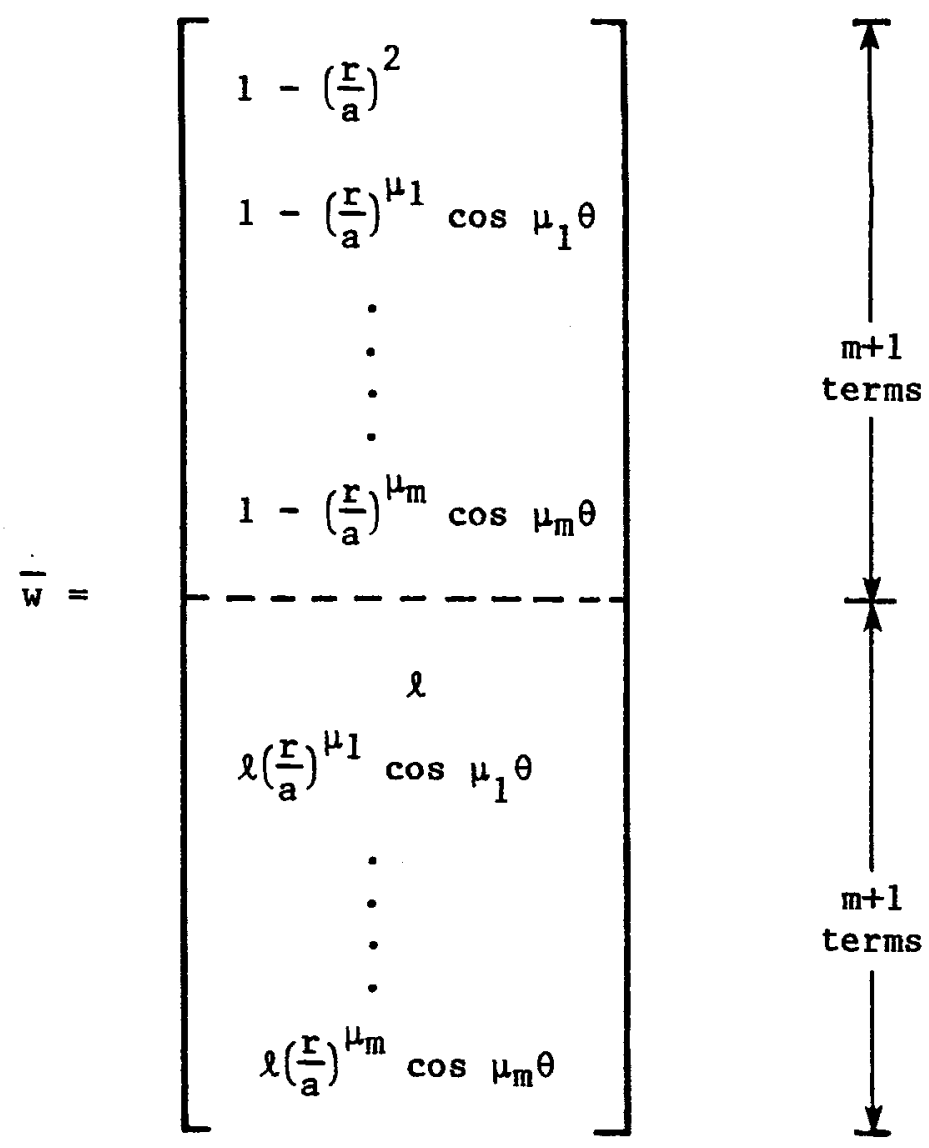

and where

$$
\mu_{k}=\frac{2 \pi k}{p} \text {. }
$$

The term $W_{j}(j=1, \ldots .3)$ contributes to $\bar{W}$ in an analogous way. For instance, consider $W_{1}$ and $W_{3}$ :

$$
W_{1}=\rho_{f} A_{f g R} \cos \gamma \int_{0}^{P} v d \theta=\lambda^{T} \rho_{f} A_{f g R} \cos \gamma \int_{0}^{p} \bar{v} d \theta
$$

and

$$
W_{3}=P \int_{0}^{p} \int_{0}^{a} w r d r d \theta=\lambda^{T} P \int_{0}^{P} \int_{0}^{a} \bar{w} r d r d \theta
$$

The values for elements of $\bar{U}$ and $\bar{W}$ are now easily determined by performing the necessary integrations, which are significantly simplified by using the orthogonal properties of the assumed displacement functions.

For completeness the matrices $\bar{U}_{j}(j=1, \ldots ., 6)$ and the vectors $\bar{W}_{j}(j=1,2,3)$ are presented here. 

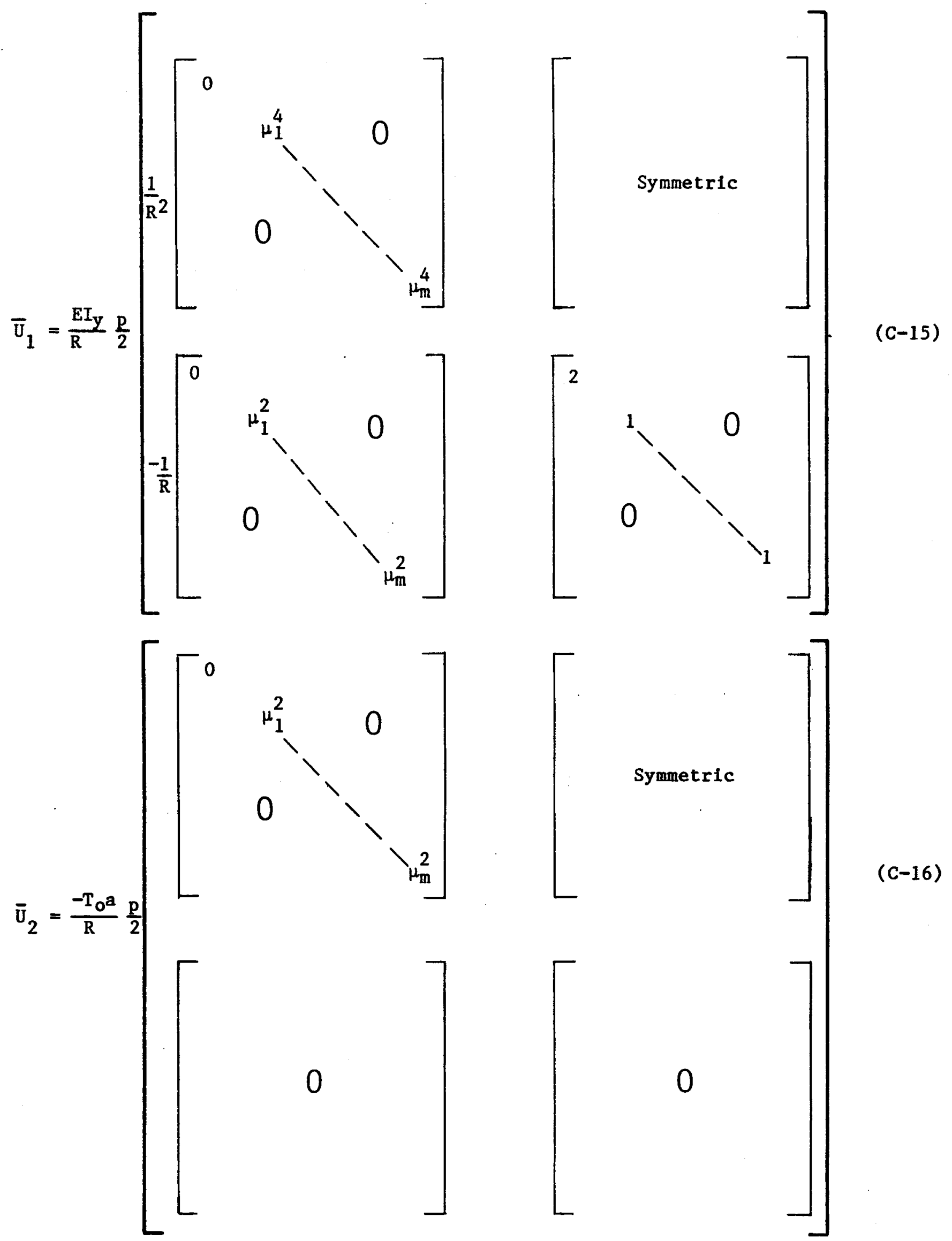


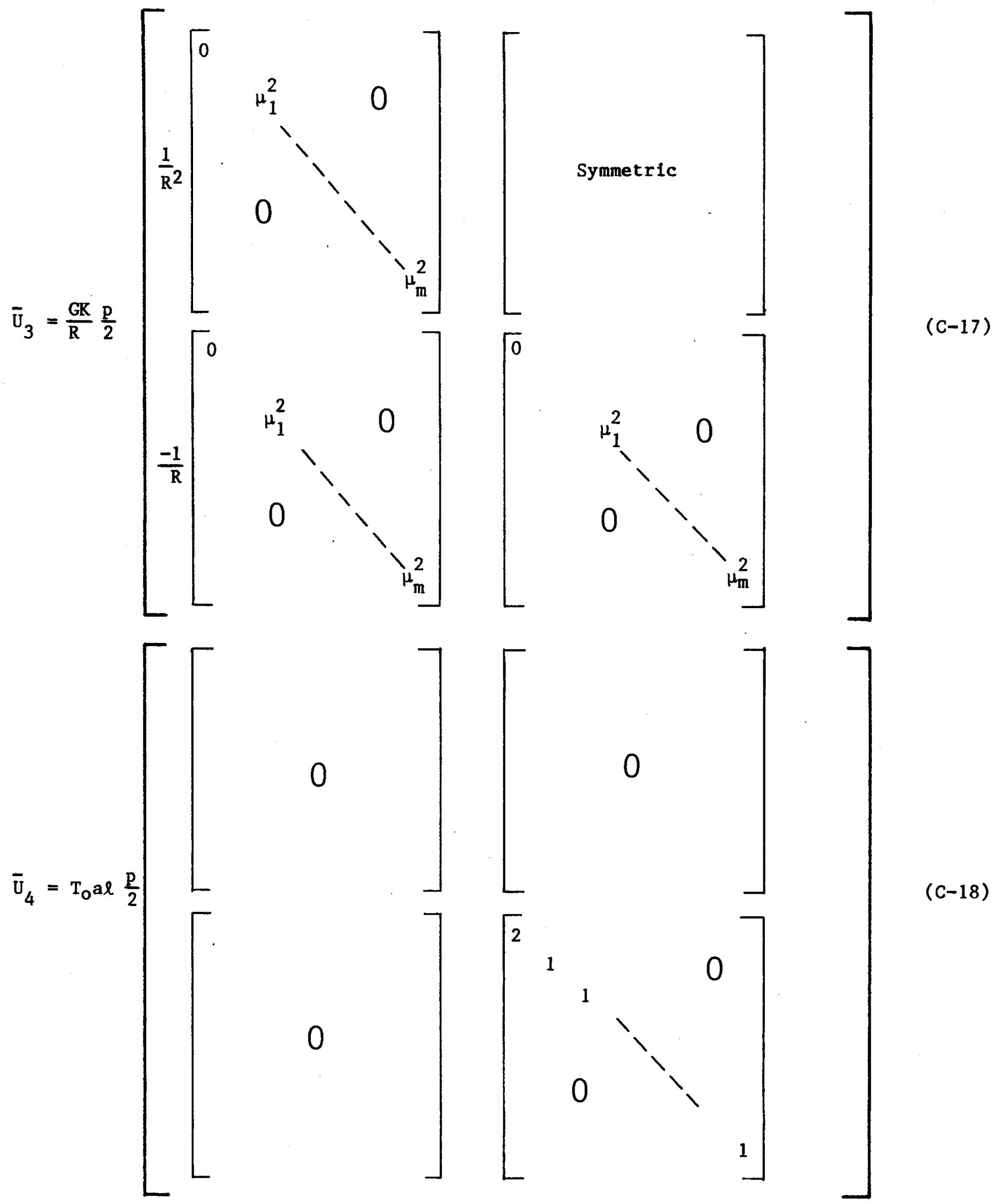


$\bar{U}_{5}$ (for fixed boundary conditions and two membranes)

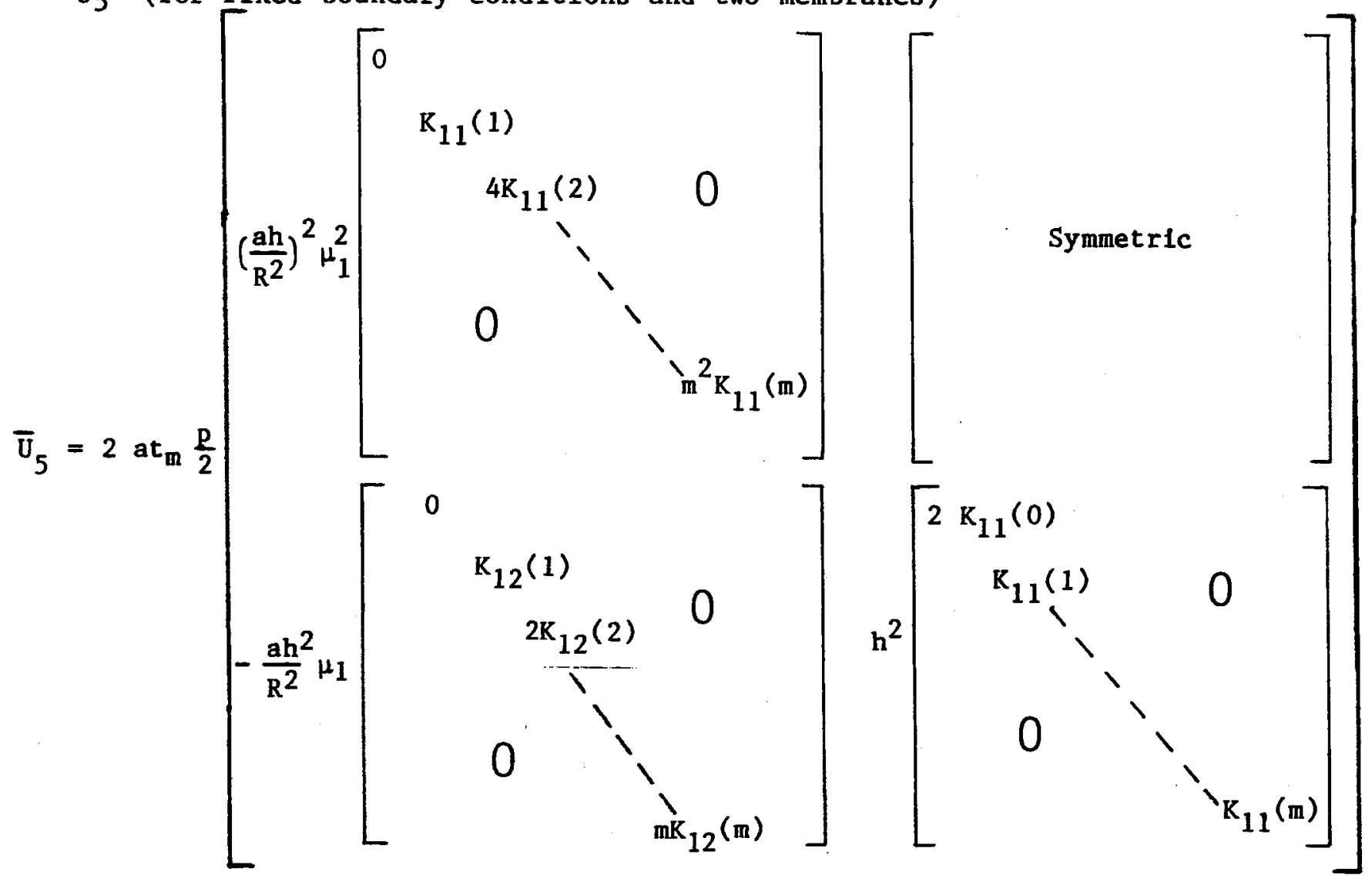

where $K_{11}(k)$ is given by Eqs. $A-14$ or $A-26$, and $K_{12}(k)$ is given by Eq. $A-15$. It is interesting to note that the upper left quadrant of $\mathrm{J}_{5}$ corresponds to the additional flange effect restraint offered by the membranes while the bottom right quadrant corresponds to the roll restraint offered by the membranes; the off diagonal quadrants correspond to the coupling between the bending and roll restraint contributions to the stiffness due to the membrane. 
$\overline{\mathrm{U}}_{5}$ (for radial constraint boundary conditions and two membranes)

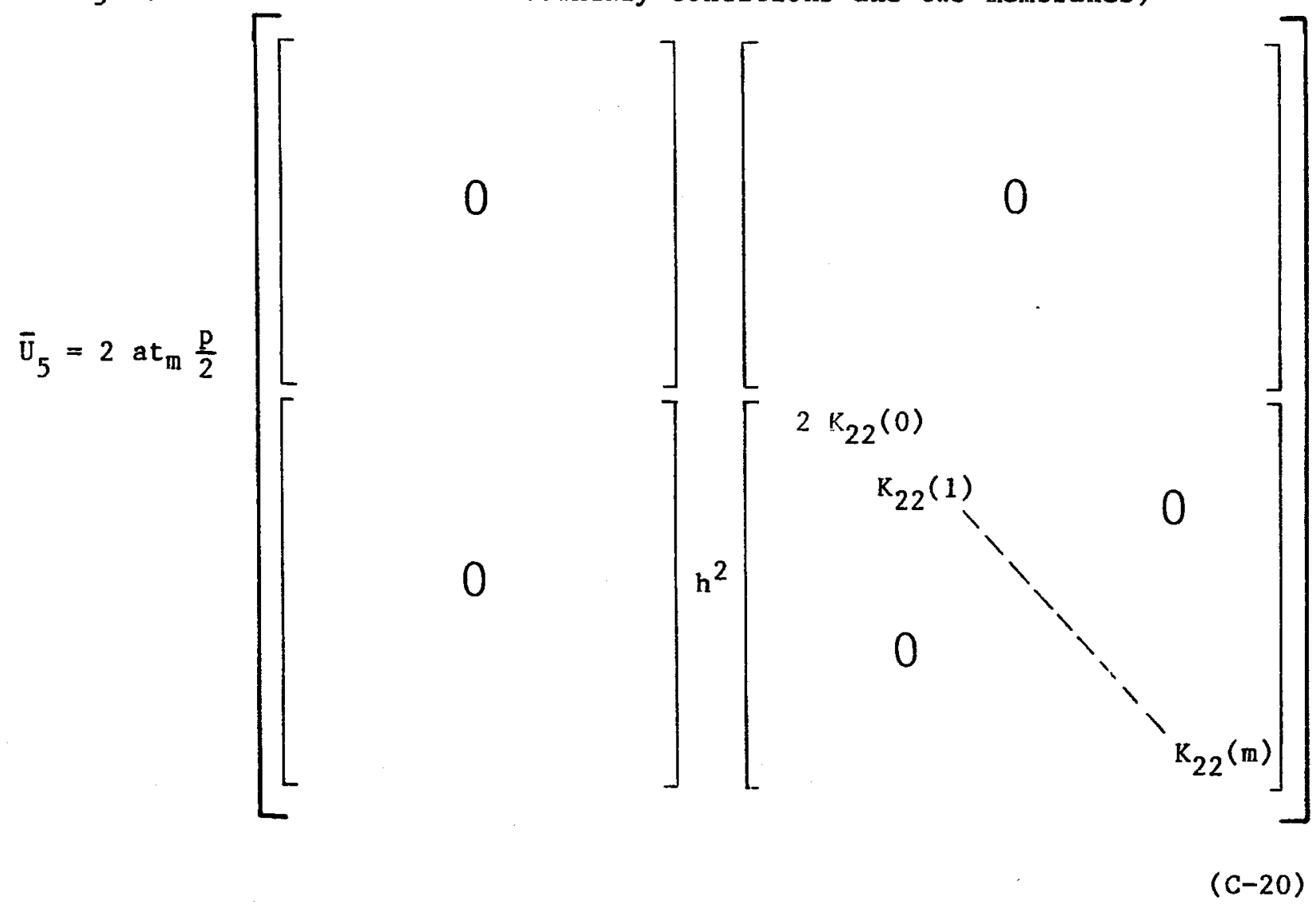

where $\left(\mathrm{K}_{22}(\mathrm{k})\right.$ is given by Eqs. A-24 or A-26 depending on the value of $\mathrm{k}$. 


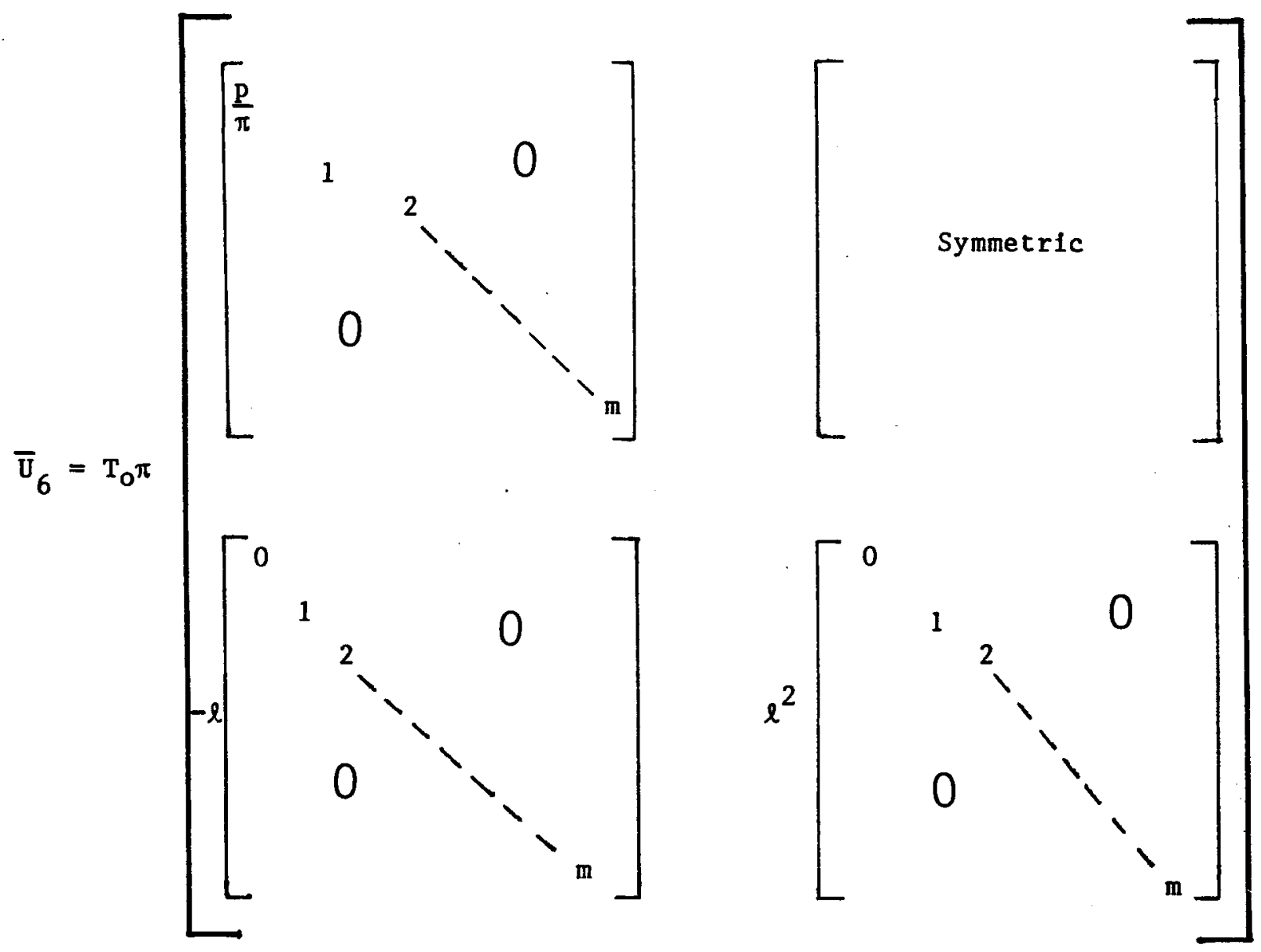

The load vectors are given by

$\overline{\mathrm{W}}_{1}^{\mathrm{T}}=\rho_{\mathrm{f}} \mathrm{A}_{\mathrm{f}} \mathrm{Rg} \mathrm{p} \cos \gamma[0,1,1, \ldots .1,0,0,0, \ldots .0]$,

$\overline{\mathrm{W}}_{2}$, for 2 membranes is defined by

$\overline{\mathrm{W}}_{2}^{\mathrm{T}}=\rho_{\mathrm{m}} \mathrm{t}_{\mathrm{m}} \mathrm{a}^{2} \mathrm{~g} \mathrm{p} \cos \gamma[1 / 2,1,1, \ldots .1, l, 0,0 . . .0]$,

and

$\overline{\mathrm{W}}_{3}^{\mathrm{T}}=\frac{\mathrm{Pa}^{2}}{2} \mathrm{p}[1 / 2,1,1, \ldots .1, \ell, 0,0, \ldots . .0]$.

Note that the stiffness matrices defined by Eqs. C-16, C-18, and C-21 are the same for efther single- or double-membrane systems (as long as the total load on the frame is $T_{0}$ ). This results from the geometric and loading symmetry assumed. The expressions for $\bar{U}_{5}$, Eqs. $C-19$ and $\mathrm{C}-20$, are different and are discussed in Appendix F. Also, for single-membrane systems the expression for $\bar{W}_{2}$, Eq. C-23, should be divided by 2 . 


\section{APPENDIX D}

SOME OTHER USEPUL QUANTITIES

The total rms surface error $\beta$ can be determined following the development presented in Murphy and Sallis,* where (see Appendix B also) they show that

$$
\beta=\frac{\iint_{s} w^{2}, r+\left(\frac{1}{r} w, \theta\right)^{2} r d r d \theta}{\pi a^{2}} .
$$

Equation D-1 corresponds to the deformation increments relative to the initial configuration and thus considers deviations from the initial shape (the initial shape may or may not be flat).

Now, comparing with Eq. 3-13 and using the notation in Eq. 4-9 we can see that $\beta$ can be written as

$$
\begin{aligned}
\beta & \left.=\left[\frac{\frac{1}{\mathrm{~T}_{0}} \lambda^{\mathrm{T}} \overline{\mathrm{U}}_{6} \lambda}{\frac{\mathrm{p}}{2} \mathrm{a}^{2}}\right]\right]^{1 / 2} \\
& =\left[2\left(\frac{\mathrm{a}_{\mathrm{o}}}{\mathrm{a}}\right)^{2}+\frac{2 \pi}{\mathrm{p}} \sum_{k=1}^{\mathrm{m}} \mathrm{k}\left(\frac{\mathrm{a}_{\mathrm{k}}-\ell \mathrm{b}_{\mathrm{k}}}{\mathrm{a}}\right)\right]^{21 / 2}=\left(\beta_{1}^{2}+\beta_{2}^{2}\right)^{1 / 2},
\end{aligned}
$$

where

$$
\beta_{1}=\left(\frac{a_{0}}{a}\right) \sqrt{2}
$$

and

$$
\beta_{2}=\left[\frac{2 \pi}{p} \sum_{k=1}^{m} k\left(\frac{a_{k}-l b_{k}}{a}\right)^{2}\right]^{1 / 2} \text {. }
$$

The terms $\beta_{1}$ and $\beta_{2}^{\prime}$ correspond to the surface error for axisymmetric and asymetric deformation, respectively. Thus, $\beta_{1}$ corresponds to the error if the pressure is applied to the membrane with the frame held rigid in the flat, undeformed condition, and $\beta_{2}$.corresponds to the error associated with the distortion of the frame only.

The frame bending $M_{y}$ and twist $M_{z}$ moments from which the frame stresses are easily derived are of interest and are determined from Eqs. 3-5, 3-8, and 4-1 through 4-4. The results are

$$
M_{y}=\frac{E I_{y}}{R} \frac{v^{\prime \prime}}{R}-\phi=\frac{E I_{y}}{R}\left[-b_{0}+\sum_{k=1}^{m}\left(\frac{a_{k} \mu_{k}{ }^{2}}{R}-b_{k}\right) \cos \mu_{k} \theta\right]
$$

*Murphy, L. M., and D. V. Saliis, Analytical Modeling and Structural Response of a Stretched-Membrane Reflective Module, SERI/TR-253-2101, Golden, CO: Solar Energy Resear,ch Institute, May 1984. 


$$
M_{z}=\frac{G K}{R}\left(\frac{v^{\prime}}{R}+\phi^{\prime}\right)=\frac{G K}{R} \sum_{k=1}^{m}\left(\frac{a_{k} \mu_{k}}{R}\right)-b_{k} \mu_{k} \sin \mu_{k} \theta .
$$

The stress increments in the membrane are determined with Eqs. A-12 through A-24, depending on the boundary conditions. For the total fixed boundary conditions we see that

$$
\tau_{r r}=h b_{0} K_{11}(0)+\sum_{k=1}^{m}\left[h b_{k} K_{11}(k)-\left(\frac{a h}{R^{2}}\right) a_{k} \mu_{k} K_{12}(k)\right] \cos \mu_{k} \theta \quad(D-7)
$$

and

$$
\tau_{r \theta}=\sum_{k=1}^{m}\left[h b_{k} k_{12}(k)-\frac{a h}{R^{2}} a_{k} \mu_{k} k_{11}(k)\right] \sin \mu_{k} \theta .
$$

For the radial-constraint-only condition we see that

$$
\tau_{r r}=\sum_{k=0}^{m} h b_{k} K_{22}(k) \cos \mu_{k} \theta
$$

and

$$
\tau_{\mathbf{r} \theta}=0
$$




\section{APPENDIX E}

\section{A TWO-TERH DESIGN APPROXIMATION}

A simple two-term approximate solution is easily derived from the model previously described. If we assume a simple single harmonic solution of the form

$$
v(\theta)=a_{1}\left(1-\cos \mu_{1} \theta\right)
$$

and

$$
\phi(\theta)=b_{1} \cos \mu_{1} \theta,
$$

then a solution is easily derived, which results in a simple $2 \times 2$ stiffness matrix. Thus, using the symmetric stiffness matrix whose components are defined by $S_{i j}(1, j=1,2)$, the solution for $a_{1}$ and $b_{1}$ can be determined from

$$
\left[\begin{array}{ll}
S_{11} & S_{12} \\
S_{12} & S_{22}
\end{array}\right]\left[\begin{array}{l}
a_{1} \\
b_{1}
\end{array}\right]=\left[\begin{array}{l}
F_{1} \\
F_{2}
\end{array}\right]
$$

or

$$
\left[\begin{array}{l}
a_{1} \\
b_{1}
\end{array}\right]=\left[\begin{array}{ll}
S_{11} & S_{12} \\
S_{21} & S_{22}
\end{array}\right]^{-1}\left[\begin{array}{l}
F_{1} \\
F_{2}
\end{array}\right]=\frac{1}{D}\left[\begin{array}{cc}
S_{22} & -S_{12} \\
-S_{12} & S_{11}
\end{array}\right]\left[\begin{array}{l}
F_{1} \\
F_{2}
\end{array}\right],
$$

where $F_{j}(j=1,2)$ are the approprlate components corresponding to the loading vector and where $D$ is defined as the determinant of the stiffness matrix:

$$
D=S_{11} S_{22}-s_{12}^{2}
$$

This simple model can be used to approximate the deformations caused by uniform pressure loading where simple supports are assumed at uniform circumferential intervals of value $p$.

Further, this model can be used to estimate the critical bifurcation tension level for the structure by solving for that tension, which will make the determinant of the stiffness matrix zero. In fact this stability prediction approach is identical to the simple eigenvalue approach used in many previous studies (Thompson 1984; TImoshento 1961).

These stiffness matrix elements in Eq. E-4 can be determined from the appropriate terms of $\overline{\mathrm{U}}_{\mathrm{j}} \cdot(\mathrm{j}=1, \ldots .6)$ from Eqs. $\mathrm{C}-15$ to $\mathrm{C}-24$.

Thus, we find that

$$
\mathrm{S}_{11}=\frac{\mathrm{p}}{2}\left[\frac{\mathrm{EI} \mathrm{y}_{\mathrm{R}}}{\mathrm{R}^{3}} \mu_{1}^{4}+\frac{\mathrm{GK}}{\mathrm{R}^{3}} \mu_{1}^{2}-\mathrm{To}_{0}\left(\frac{\mathrm{a}}{\mathrm{R}} \mu_{1}^{2}-\mu_{1}\right)+\mathrm{at}_{\mathrm{m}} \mathrm{K}_{\mathrm{AA}}\right]
$$




$$
\begin{aligned}
& S_{12}=S_{21}=\frac{p}{2}\left[-\left(\frac{E I_{y}}{R^{2}}+\frac{G K}{R^{2}}\right) \mu_{1}^{2}-T o \mu_{1} \ell-a t_{m} K_{A B}\right] \\
& S_{22}=\frac{P}{2}\left[\frac{E I_{y}}{R}+\frac{G K}{R} \mu_{1}^{2}+T o\left(\mu_{1} \ell^{2}+a l\right)+a t_{m} K_{B B}\right],
\end{aligned}
$$

where as before

$$
\mu_{1}=\frac{2 \pi}{p} \text {. }
$$

The terms $\mathrm{K}_{\mathrm{AA}}$, $\mathrm{K}_{\mathrm{BB}}$, and $\mathrm{K}_{\mathrm{AB}}$ correspond to the double-membrane case (set to zero otherwise) and are defined in Table E-1. Here, it is seen that $\mu_{1}$ corresponds to the number of waves around the circumference where exactly one wave occurs between adjacent supports.

The load components are determined from $\bar{w}_{j}(j=1,2,3)$ and are found to be

$$
F_{1}=p g \cos \gamma\left(\rho_{f} A_{f}^{R}+\rho_{m} t_{m}{ }^{2}\right)
$$

and

$$
\mathrm{F}_{2}=0 \text {. }
$$

Here, we assume that the $b_{0}$ term is zero (i.e., no uniform twist). The axisymmetric deformation can be easily estimated and superimposed on the solutions corresponding to $a_{1}$ and $b_{1}$. Thus, $a_{0}$ is found to be

$$
a_{0}=\frac{P a^{2}}{4 T}
$$

where $P$ and $T$ correspond to the net pressure load on and the tension in the membrane of interest, respectively.

Table B-1. Membrane Stiffness Coefficients

\begin{tabular}{ccc}
\hline & $\begin{array}{c}\text { Totally Fixed } \\
\text { Constraint }\end{array}$ & Radial Only Constraint \\
\hline $\mathrm{K}_{\mathrm{AA}}(\mathrm{n})$ & $2\left(\frac{\mathrm{ah}}{\mathrm{R}^{2}}\right)^{2} \mu_{1}^{2} \mathrm{~K}_{11}(\mathrm{n})$ & 0 \\
$\mathrm{~K}_{\mathrm{AB}}(\mathrm{n})$ & $2 \frac{\mathrm{ah}}{\mathrm{R}^{2}} \mu_{1} \mathrm{~h} \mathrm{~K}_{12}(\mathrm{n})$ & 0 \\
$\mathrm{~K}_{\mathrm{BB}}(\mathrm{n})$ & $2 \mathrm{~h}^{2} \mathrm{~K}_{11}(\mathrm{n})$ & $2 \mathrm{~h}^{2} \mathrm{~K}_{22}(\mathrm{n})$ \\
\hline
\end{tabular}




\section{DISTRIBUTION LIST}

ARCO Power Systems

9315 Deering

Chatsworth, CA

Mr. Jim Caldwell

Acurex Solar Corporation

485 Clyde Ave.

Mt. View, CA 94042

Mr. Don Duffy

Mr. John Schaeffer, Ph.D.

Advanco Corporation

40701 Monterey Ave.

Palm Desert, CA 92260

$\mathrm{Mr}$. Byron Washom

A1lied Chemical Company

P.0. Box 1021R

Morristown, NJ 07960

Mr. Robert Armburst

Arizona Public Service Company

P.0. Box 21666

Phoenix, AZ 85036

Mr. Eric Weber

BDM Corporation

1801 Randolph SE

Albuquerque, NM 87106

Mr.

Babcock and Wilcox

91 Stirling Ave.

Barberton, OH 44203

Mr. Paul Elsbree

Barber-Nichols Engineering Co. 6325 W. 55th Ave.

Arvada, CO 80002

Mr. Robert Barber

Battelle Pacific NW Laboratory P.0. Box 999

Richland, WA 99352

Dr. Ben Johnson

Bechte1 Corporation

P.0. Box 3965

San Francisco, CA 94119

Mr. Peter Delaquil

\author{
Black and Veatch Consulting \\ Engineers \\ 1500 Meadow Lake Parkway \\ Kansas City, MO 64114 \\ Dr. Charles Grosskreutz \\ Boeing Engineering \& \\ Construction $\mathrm{Co}$. \\ Ma11 Stop 9A-42 \\ Post Office 3707 \\ Seattle, WA 98125 \\ Mr. Don Bartlett \\ Bowman, Dr. Melvin \\ Consultant \\ 360 Andanada \\ Los Alamos, NM 87544 \\ Brandt, Dr. Richard \\ Consu1tant \\ University of Washington \\ Robert Hall \\ Seattle, WA 98195 \\ Brookhaven National Laboratory \\ Department of Applied Sciences \\ Bullding 701 \\ Upton, NY 11973 \\ Dr. William Wilhelm \\ Brumleve, Dr. Tom \\ Consultant \\ 1512 N. Gate Road \\ Walnut Creek, CA 94598 \\ Burns and McDonnel1 \\ P.0. Box 173 \\ Kansas C1ty, MO 64141 \\ Mr. Peter Steitz \\ Colorado State University \\ ERC \\ Ft. Collins, CO 80523 \\ Dr. John Peterka \\ Dan-Ka Products, Inc. \\ 1135 S. Jason Street \\ Denver, CO 80223 \\ Mr. Daniel Sal1is
}


Department of Aerospace \& Mechanical Eng.

Engineering Experiment State University of Arizona

Tuscon, AZ 85721

Mr. Kumar Romahalli, Ph.D.

Assoclate Professor

Department of Civil Engineering

Colorado State University

Ft. Collins, CO 80523

Mr. Jon Peterka, Ph.D.

Professor, Civil Englneering

Department of Civil Engineering

University of Nebraska

60th \& Dodge Street

Omaha, NE 68182-0178

Mr. Chris Tuan, Ph.D.

Department of Energy/ALO

P.0. Box 1500

Albuquerque, NM 87115

Mr. Dean Graves

Mr. Joe Welsiger

Mr. Nyles Lackey

Department of Energy/HQ

1000 Independence Ave., SW

Washington, DC 20585

Dr. H. Coleman

Mr. S. Gronich

Mr. C. Mangold

Mr. M. Scheve

Mr. Frank Wilkins

Department of Energy/SAN

1333 Broadway

Oakland, CA 94536

Mr. Robert Hughey

$\mathrm{Mr}$. William Lambert

Department of Energy/SAO

1617 Cole Blvd.

Golden, CO 80401

Mr. Dave Rardin

Dow Chemical Company

Contract Research, Devel. and Engr.

Building 566

Midland, MI 48640

Mr. J. F. Mu11oy
Dow Corning Corporation

Midland, MI 48640

Mr. G. A. Lane

E1 Paso Electric

P.0. Box 982

EI Paso, TX 79960

Mr. James E. Brown

Electric Power Research Institute

P.0. Box 10412

Palo Alto, CA 94303

Mr. Donald Augenstein

England, Dr. Christopher

Consultant

Engineering Research Group

138 West Pomona Ave.

Morrovia, CA 91016

Entech, Incorporated

P.O. Box 612246

DFW Afrport, TX 75261

Mr. Walter Hesse

Falconer Glass Industries, Inc. 500 South Work Street

Falconer, NY 14733-1787

Mr. Jack South

Farmland Industries

P.0. Box 69

Lawrence, KS 66044

Mr. John Prijatel

Foster Wheeler Solar Development Corp.

12 Peach Tree H1ll Road

Livingston, NJ 070.70

Mr. Robert J. Zoschak

Gas Research Institute

8600 West Bryn Mawr Ave.

Chicago, IL 60631

Mr. Kelth Davidson

Georgia Institute of Technology

Atlanta, GA 30332

Mr. Robert Cassanova 
Georgia Power Company

7 Solar Circle

Shenandoah, GA 30265

Mr.

HMJ Corporation

P.O. Box 15128

Chevy Chase, MD 20815

Mr. William D. Jackson

Hughes Aircraft Company

Electric Optical Data Systems Group

E1 Segundo, CA 90245

Dr. Frank Ludwig

Jet Propulsion Laboratory

480 Oak Grove Drive

Pasadena, CA 91109

Mr. John Lucas, Ph.D.

LaJet Energy Company

P.0. Box 3599

Abilene, TX 79604

Mr. Monte McGlaun

Lawrence Berkeley Laboratory

Building 90-2024,

University of Calffornia

1 Cyclotron Road

Berkeley, CA 94720

Dr. Arlan Hunt

Luz Engineering Corp.

15720 Ventura B1vd.

Suite 504

Encino, CA 91436

Dr. David Kearney

Martin Marietta

P.0. Box 179

Denver, CO 80201

Mr. Tom Tracey

McDonne11 Douglas Astronautics

Company

5301 Bolsa Ave.

Huntington Beach, CA 92647

Mr. Jim Rogan

Mr. Lee Weinstein
Mechanical Technology, Inc.

968 Albany Shaker Road

Latham, NY 12110

Mr. H. M. Leibowtiz

Mr. G. R. Dochat

Meridian Corporation

5113 Leesburg Pike

Suite 700

Falls Church, VA 22041

Mr. Dinesh Kumar

Midwest Research Institute

425 Volker Blvd.

Kansas City, MO 64110

Mr. R. L. Martin

Mr. Jim Williamson

Mt. Moriah Trust

6200 Plateau Drive

Englewood, Co 80111

Mr. Kenell J. Touryan, Ph.D.

Vice President, R\&D

NASA Lew is Research Center

21000 Brookpark Road

Cleveland, OH 44135

Dr. Dennis Flood

NASA-Johnson Space Center

NASA Road One - EPS

Houston, TX 77058

Mr. William Simon

National Bureau of Standards

Building 221, Room 252

Gaithersburg, MD 20899

Mr. Joseph Richmond

New Mexico State University

Physical Sclences Lab

P.0. Box 3548

Las Cruces, NM 88003

Mr. James McCrary

Olin Corporation

315 Knotter Drive

Cheshire, CT 06410-0586

Mr. Jack Rickly

Pacific Gas and Electric Company

Mr. Gerry Braun 
Power KInetics, Inc.

1223 Peoples Ave.

Troy, NY 12180

Mr. Bob Rogers

Purdue University

Mechanical Engineering Bullding

West Lafayette, IN 47907

Mr. J. T. Pearson, Ph.D.

Rockwel1 International

Energy Systems Group

8900 De Soto Ave.

Canoga Park, CA 91304

Mr. Tom H. Springer

Rockwe11 Internationa1 Corp

Energy Technology Center

P.0. Box 1449

Canoga Park, CA 91304

Mr. W. L. Bigelow

Sanders Associates, Inc.

95 Canal Street

Nashua, NH 03010

Mr. Danle1 J. ShIne

Sandia National Laboratories

Division 1523

Post Office Box 5800

Albuquerque, NM 87115

Mr. Rob Reuter, Ph.D.

Sandia National Laboratories

Solar Department 8453

Livermore, CA 94550

Mr. B111 Delemeter, Ph.D.

Mr. Joe Iannucc1

Mr. J. C. Swearengen

Mr. A Skinrood

Mr. R. A. Rinne

Sandia National Laboratories Solar Energy Department 6220

P.0. Box 5800

Albuquerque, NM 87185

Mr. John Otts

Mr. James Leonard

Mr. Donald Schuler

University of Arizona
Sandia National Laboratories

Post Office Box 969

Livermore, CA 94550

Mr. Mel Calabressi, Ph.D.

Mr. Clay Mavis

Ms. Vera Reve111, Ph.D.

Mr. Jack Swearingen, Ph.D.

Sclence Applications, Inc. 10401 Rosselle Street

San Diego, CA 92121

Dr. Barry Butler

Solar Energy Industries Association 1717 Massachusetts Ave. NW No. 503 Washington, DC 20036

Mr. Carlo LaPorta

Mr. David Goren

Mr. Hal Seilstad

Solar Energy Research Institute 1617 Cole Blvd. Golden, CO 80401

Mr. B. P. Gupta

Dr. L. J. Shannon

Solar Kinetics, Inc.

P.0. Box 47045

Da11as, TX 75247

Mr. Gus Hutchison

Southern Research Institute

2244 Walnut Grove Ave.

Rosemead, CA 91770

Mr. Joe Reeves

Southwest Research Institute

6220 Culebra Road

San Antonio, TX 78238

Mr. Danny M. Deffenbaugh

Stirling Thermal Motors, Inc. 2841 Boardwalk

Ann Arbor, MI 48104

Mr. Benjamin Ziph

Texas Tech University

Dept. of Electrical Engineering

Lubbock, TX 79409

Mr. Edgar A. O'Hair

Physics Department

Ms. Virginia K. Agarwal

College of Engineering 
Tucson, AZ 95721

Dr. Kumar Ramoha111

University of Arizona

Dept. of Electrical Engineering

Tucson, AZ 85721

Dr. Roger Jones

University of Chicago

Enrico Ferni Institute

5640 S. E111s Ave.

Chicago, IL 60637

Dr. R. Winston

Dr. J. Gallagher

University of Dayton Research

Institute

300 College Park, KL102

Dayton, OH 45469

Dr. Barry H. Dellinger

University of Hawail at Manoa

Hawail Natural Energy Institute

Homes Hall Room 246

2540 Dole Street

Honolulu, HI 96822

Dr. Mike Antal

University of Houston

4800 Calhoun

106 SPA Building

Houston, TX 77004

Dr. Alvin Hildebrandt

Dr. Lorin Vant-Hull

University of Illinois

Dept. of Mechanical and Industrial

Engineering

1206 W. Green Street

Urbana, IL 61801

Dr. Art Clausing

University of Kansas Center for

Research

2291 Irving Hill Drive

Lawrence, KS 66045

Mr. David Martin
University of Minnesota

Dept. of Mechanical Engineering

Minneapolis, MN 55455

Dr. Edward Fletcher

University of New Hampshire and

College of Engineering and Physical

Sciences

Kingsbury Hall - 260

Durham, NH 03824

Dr. V. K. Mathur

University of New Mexico

Department of Mechanical Engineering

Albuquerque, NM 87131

Mr. M. W. Wilden

Mr. W. A. Gross

Wichita State University

Mechanical Engineering Dept.

Wichita, KS 67208

Mr. James A. Harris

3M Corporation

$3 M$ Center Bullding, 207-1W-08

St. Pau1, MN 55101

Mr. David Hill

Mr. Burton A. Benson

Solar Energy Research Institute

John Anderson

Meir Carasso

Gordon Gross

Bim Gupta

Dave Johnson

Ken Olsen

Larry Shannon

Dave SImms

John Thornton

Rick Wood 


\begin{tabular}{|c|c|c|}
\hline $\begin{array}{c}\text { Document Control } \\
\text { Page }\end{array}$ & \begin{tabular}{|l|l|} 
1. SERI Report No. & 2. NTIS Accession No. \\
SERI/TR-253-2626 & \\
\end{tabular} & 3. Recipient's Accession No. \\
\hline \multirow{2}{*}{\multicolumn{2}{|c|}{$\begin{array}{l}\text { 4. Title and Subtitle } \\
\text { A Variational Approach for Predicting the Load } \\
\text { Deformation Response of a Double Stretched } \\
\text { Membrane Reflector Module }\end{array}$}} & $\begin{array}{l}\text { 5. Publication Date } \\
\text { October 1,985 }\end{array}$ \\
\hline & & 6. \\
\hline \multicolumn{2}{|l|}{$\begin{array}{l}\text { 7. Author(s) } \\
\text { L. M. Murphy }\end{array}$} & 8. Performing Organization Rept. No. \\
\hline \multirow{2}{*}{\multicolumn{2}{|c|}{$\begin{array}{l}\text { 9. Performing Organization Name and Address } \\
\text { Solar Energy Research Institute } \\
1617 \text { Cole Boulevard } \\
\text { Golden, Colorado } 80401\end{array}$}} & $\begin{array}{l}\text { 10. Project/Task/Work Unit No. } \\
5102.31\end{array}$ \\
\hline & & $\begin{array}{l}\text { 11. Contract (C) or Grant (G) No. } \\
\text { (C) } \\
\text { (G) }\end{array}$ \\
\hline \multirow{2}{*}{\multicolumn{2}{|c|}{ 12. Sponsoring Organization Name and Address }} & $\begin{array}{c}\text { 13. Type of Report \& Period Covered } \\
\text { Technica] Report }\end{array}$ \\
\hline & & 14 \\
\hline \multicolumn{3}{|l|}{ 15. Supplementary Notes } \\
\hline \multicolumn{3}{|c|}{$\begin{array}{l}\text { 16. Abstract (Limit: } 200 \text { words) } \\
\text { This report presents an anaiytical model useful for design and sizing purposes to } \\
\text { describe the load deformation response of a stretched membrane reflector module } \\
\text { structural system. The major problem addressed is that of a double membrane module } \\
\text { which is uniformly loaded normal to the membrane surface. The membranes are attach } \\
\text { ed to a frame which is held fixed by periodic simple supports. The current model } \\
\text { predicts the coupled membrane/frame response and considers the in-plane stiffness } \\
\text { effect of the membrane and nonuniform tension states in the membrane; the effect of } \\
\text { different attachment schemes; and the impact of double-membrane designs. The ten- } \\
\text { sion increments in the membrane are assumed to be small compared to the initial } \\
\text { membrane pre-tension. The model developed in this report is based on an incremen- } \\
\text { tal variational approach where large deformation, small strain theories are assumed } \\
\text { The Rayleigh Ritz procedure and a formalism similar to that used in finite element } \\
\text { analyses are employed in describing the system stiffness. Increased system struc- } \\
\text { tural stiffness is shown to accrue with the coupled double membrane frame system by } \\
\text { virtue of the roll restraint and frame bending rigidity enhancements (analogous to } \\
\text { to that due to a flange section) offered to the fram by the membrane. Results are } \\
\text { compared with predictions using detailed finite element analyses. }\end{array}$} \\
\hline \multicolumn{3}{|c|}{$\begin{array}{l}\text { 17. Document Analysis } \\
\text { a. Descriptors Deformation } \\
\text { Membranes ; Potentia. } \\
\text { b. Identifiers/Open-Ended Terms }\end{array}$} \\
\hline \multicolumn{3}{|l|}{ c. UC Categories } \\
\hline \multicolumn{3}{|l|}{$62 a, c$} \\
\hline \multirow{2}{*}{\multicolumn{2}{|c|}{$\begin{array}{l}\text { 18. Availability Statement } \\
\text { National Technical Information Service } \\
\text { U.S. Department of Commerce } \\
5285 \text { Port Royal Road } \\
\text { Springfield, Virginia } 22161\end{array}$}} & $\begin{array}{l}\text { 19. No. of Pages } \\
60\end{array}$ \\
\hline & & $\begin{array}{r}\text { 20. Price } \\
\text { A04 }\end{array}$ \\
\hline
\end{tabular}

